\title{
CIBELE MENDES
}

Prática em transfusão de glóbulos vermelhos e índice de oxigenação em um centro de terapia intensiva pediátrico

Dissertação apresentada à Faculdade de Medicina da Universidade de São Paulo para obtenção do título de Mestre em Ciências

Área de concentração: Pediatria

Orientador: Dr. Eduardo Juan Troster

SÃO PAULO

2007 


\section{Dedicatória}

Ao meu filho, Renan, que foi privado de minha companhia e atenção por tantos anos, quando ainda era tão pequeno e não tinha sequer o entendimento do que tudo isto significava. Espero que, um dia, ele possa compreender o que este trabalho representou e possa orgulhar-se desta vitória. Torço para que ele cresça consciente de que nunca deixou de estar em meus pensamentos e em meu coração. 


\section{Agradecimentos Especiais}

Agradeço ao meu querido orientador, Dr. Eduardo Juan Troster, meu maior incentivador e parceiro, por sua participação neste projeto. Sem seu apoio, não teria chegado ao fim. Nos momentos de dúvidas, contei com sua inteligência e praticidade. Nos momentos de fraqueza, pude contar com suas palavras de encorajamento. Nos momentos de angústia, recebi seu apoio e amizade. Sempre soube respeitar meus limites, sem, no entanto, deixar de cobrar devidamente os resultados desejados. Admiro suas qualidades e sua maneira de apoiar e ajudar aqueles que o cercam.

Agradeço ao meu pai, Francisco Mendes, por ser a pessoa maravilhosa e inigualável que é, com seu bom humor e otimismo constantes, sua honestidade e nobreza de caráter. Conseguiu me transmitir lições que levarei por toda a vida.

Agradeço a minha mãe, Nair, por ter me ensinado que a dedicação aos estudos e a inteligência devem sempre ser usadas a favor do bem. Ensinou-me que a liberdade e a independência são os bens mais preciosos na vida de uma mulher. Admiro sua praticidade, seu dinamismo e sua dedicação à família.

Por último, mas não com menor importância, agradeço ao Flávio por sua paciência infinita e por suas palavras de encorajamento nos momentos difíceis desta jornada. Mostrou-se uma companhia maravilhosa e tem me ensinado, a cada dia, a importância de um amor tão grande e tão dedicado, amor maior que o mundo. 


\section{Agradecimentos}

A todos aqueles que contribuíram, de alguma forma, para a realização deste trabalho.

Aos pequenos pacientes internados que participaram deste estudo, sem os quais o mesmo não teria sido possível.

A toda minha família, pelos momentos de apoio ao longo de todos estes anos.

Ao Prof. Dr. Flávio Adolfo Costa Vaz, pelo incentivo dado para a realização do estudo.

À amiga Cristiane Freitas Pizarro, que foi a primeira a me incentivar e a me ensinar o caminho das pedras para chegar até aqui. Por trás de sua calma e doçura esconde-se uma mulher forte e determinada.

Aos amigos do Hospital Mário Covas de Santo André, agradeço os muitos momentos de alegria que tornaram estes últimos anos mais leves e felizes.

Aos amigos do Hospital Estadual de Diadema, em especial à Eliane Takabatake e Ellen Dantas, pelo apoio, amizade e pelos tantos momentos de "terapia de grupo".

Aos amigos do Hospital Municipal Universitário de São Bernardo do Campo, em especial ao Adriano Meneghini por sua amizade sincera e por seus conselhos valiosos. 
À querida amiga Luciana Reis Carpanez, por sua ajuda na confecção desta tese e por sua amizade tão preciosa.

Ao Dr. Crésio, Dr. Antônio Carlos Alves Cardoso e Dr. Ulysses Doria Filho, pelas orientações referentes à metodologia, epidemiologia e estatística.

À equipe do Instituto da Criança, por sua enorme dedicação no tratamento de crianças tão gravemente enfermas.

Às funcionárias da biblioteca do Instituto da Criança, em especial à Mariza e Lu, por sua ajuda sempre tão solícita.

A todos meus amigos pelas palavras de incentivo, pela troca de conhecimento, pelo apoio emocional e pelos momentos de alegria.

Agradeço também àqueles que trabalharam e permitiram que este projeto se concretizasse: equipe do arquivo médico (SAME), Nivaldo e Milene (reprografia do ICr) e Adriana e Solange (secretaria da pós-graduação).

A todos, meus sinceros agradecimentos. 
Esta dissertação está de acordo com:

Referências: adaptado de International Comittee of Medical Journals Editors (Vancouver)

Universidade de São Paulo. Faculdade de Medicina. Serviço de Biblioteca e Documentação Guia de apresentação de dissertações, teses e monografias. Elaborado por Anneliese Carneiro da Cunha, Maria Julia de A. L. Freddi, Maria F. Crestana, Marinalva de Souza Aragão, Suely Campos Cardoso, Valéria Vilhena. São Paulo: Serviço de Biblioteca e Documentação, 2001.

Abreviaturas dos periódicos de acordo com List of Journals Indexed in Index Medicus. 


\section{SUMÁRIO}

Lista de abreviaturas, símbolos e siglas

Resumo

Summary

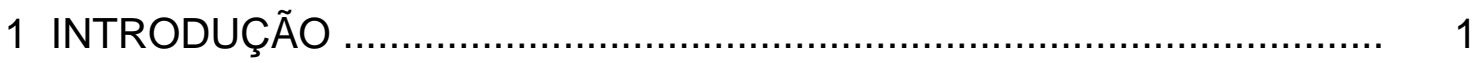

1.1 História das transfusões ............................................................. 2

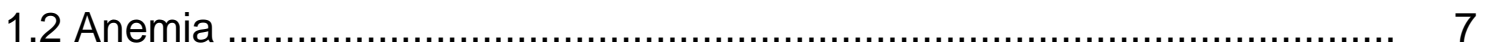

1.3 Transfusões de glóbulos vermelhos ............................................... 10

1.3.1 Dados epidemiológicos e diretrizes .............................................. 10

1.3.2 Indicações das transfusões ........................................................... 13

1.3.3 Benefícios das transfusões de glóbulos vermelhos............................. 16

1.3.4 Riscos das transfusões de glóbulos vermelhos ................................. 22

1.4 Revisão Bibliográfica .................................................................. 25

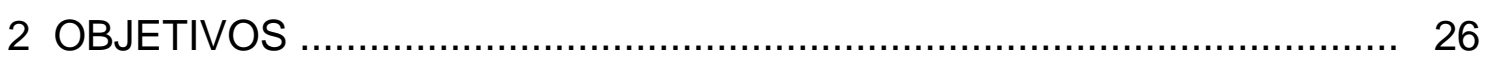

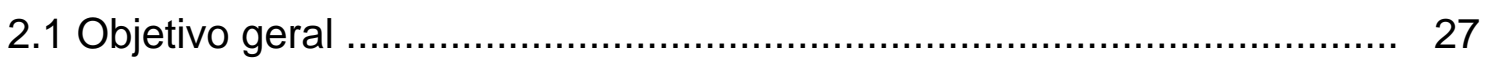

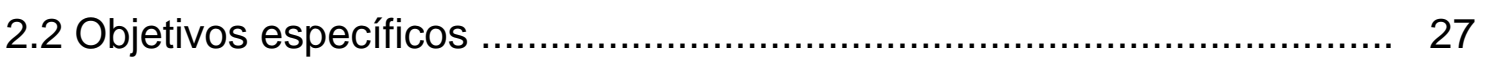

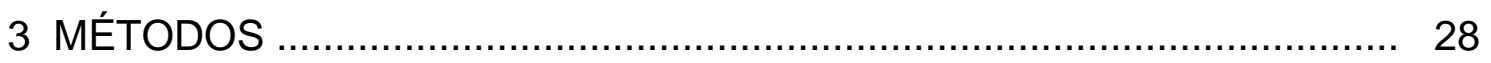

3.1 Local do estudo ....................................................................... 29

3.2 Delineamento do estudo .............................................................. 30

3.3 População estudada .................................................................... 30

3.3.1 Critérios de inclusão .................................................................. 30

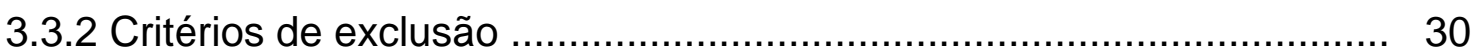

3.4 Descrição dos dados coletados ........................................................ 31

3.5 Análise estatística ............................................................................. 34

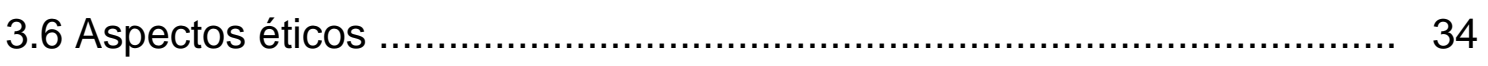




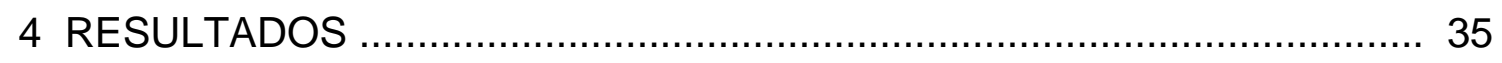

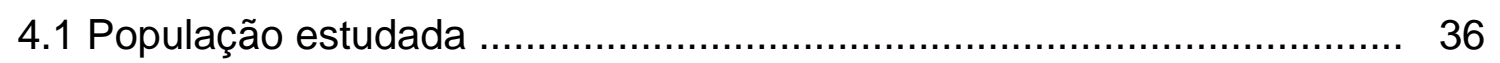

4.2 Pacientes transfundidos .............................................................. 37

4.3 Eventos transfusionais ................................................................. 39

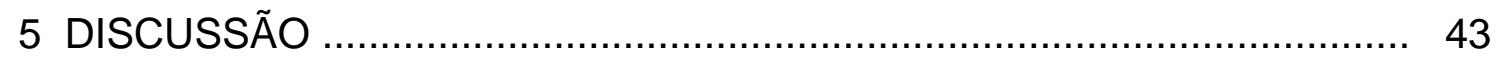

5.1 Sobre os métodos ......................................................................... 44

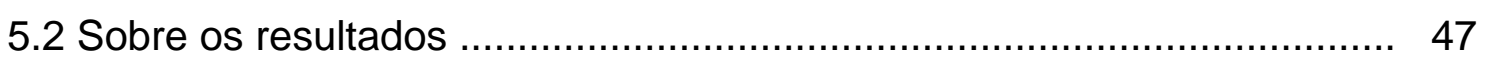

5.2.1 População estudada ................................................................ 47

5.2.2 Pacientes transfundidos ........................................................... 49

5.2.3 Eventos transfusionais ............................................................... 50

5.3 Considerações finais ................................................................. 56

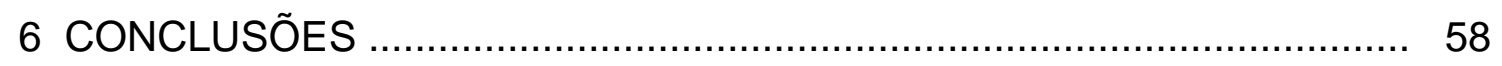

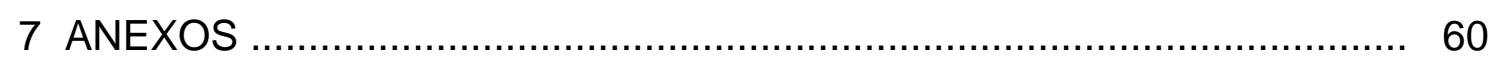

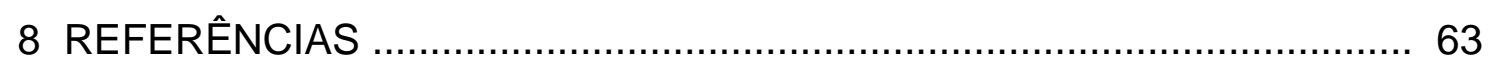




\section{LISTA DE ABREVIATURAS, SÍMBOLOS E SIGLAS}

a.C. antes de Cristo

AIDS Síndrome da Imunodeficiência Adquirida

CTI Centro de Terapia Intensiva

CTIP Centro de Terapia Intensiva Pediátrico

DMOS Disfunção de Múltiplos Órgãos e Sistemas

et al. e outros

g/dl grama por decilitro

$\mathrm{Hb} \quad$ Concentração de hemoglobina

HCFMUSP Hospital das Clínicas da Faculdade de Medicina da Universidade de São Paulo

HIV Vírus da Imunodeficiência Humana

HT Taxa de hematócrito

$\mathrm{ICr} \quad$ Instituto da Criança

kg Kilograma

$\mathrm{ml} \quad$ mililitro

n Número

$\mathrm{O}_{2} \quad$ Oxigênio

$\mathrm{PaO}_{2} \quad$ Pressão parcial de oxigênio

SAME Serviço de arquivo médico e estatístico

SIRS Síndrome da resposta inflamatória sistêmica

$\mathrm{SaO}_{2} \quad$ Saturação arterial de oxigênio

$\mathrm{SvO}_{2} \quad$ Saturação venosa de oxigênio 


\section{RESUMO}

Mendes C. Prática em transfusão de glóbulos vermelhos e índice de oxigenação em um centro de terapia intensiva pediátrico. [dissertação]. São Paulo: Faculdade de Medicina, Universidade de São Paulo; 2007. 73p

A anemia é a causa primária de indicação de transfusão de glóbulos vermelhos e é especialmente prevalente e esperada em centros de terapia intensiva. Os benefícios das transfusões incluem aumento da oxigenação tissular, diminuição de hemorragias, tratamento da anemia e da hipovolemia. Os poucos estudos publicados têm demonstrado variações significativas nas práticas de transfusões de glóbulos vermelhos e o melhor momento para a indicação destas transfusões ainda não foi identificado. Objetivos Descrever a população de crianças que recebeu transfusão de glóbulos vermelhos com relação à faixa etária, concentração de hemoglobina $(\mathrm{Hb})$ e taxa de hematócrito $(\mathrm{HT})$, uso de saturação venosa central de oxigênio $\left(\mathrm{SvO}_{2}\right)$, lactato sérico arterial, procedimentos terapêuticos e presença de disfunção de múltiplos órgãos e sistemas (DMOS). Métodos Estudo retrospectivo observacional, realizado no Centro de Terapia Intensiva Pediátrico (CTIP) do Instituto da Criança da Faculdade de Medicina da Universidade de São Paulo, em 2004, com crianças que receberam transfusão de glóbulos vermelhos. Descrevemos o número de pacientes, faixa etária, motivo de internação no CTIP, presença de doença de base e de DMOS, uso de $\mathrm{SvO}_{2}$, lactato sérico arterial, $\mathrm{Hb}, \mathrm{HT}$ e procedimentos terapêuticos (ventilação mecânica, drogas vasoativas e métodos de substituição renal). Resultados A transfusão de glóbulos vermelhos foi realizada em $50 \%$ dos pacientes internados. A idade mediana foi de 18 meses e o principal motivo de internação foi insuficiência respiratória (35\% dos casos). Doença de base estava presente em $84 \%$ dos casos e DMOS em $47 \%$ dos casos. Foram realizadas coletas de $\mathrm{Hb}$ e $\mathrm{HT}$ em todos os casos e de $\mathrm{SvO}_{2} \mathrm{e}$ lactato sérico arterial em $24 \%$ dos casos. A mediana de $\mathrm{Hb}$ pré-transfusional foi de $7,8 \mathrm{~g} / \mathrm{dl}$. Os pacientes transfundidos estavam sendo submetidos a algum 
procedimento terapêutico em $82 \%$ dos casos. Conclusões São realizadas transfusões de glóbulos vermelhos em todas as idades. A concentração de hemoglobina e a taxa de hematócrito são os principais dados utilizados para a indicação destas transfusões. O lactato sérico arterial e a $\mathrm{SvO}_{2}$ são pouco utilizados para se indicar a transfusão de glóbulos vermelhos. A maioria dos pacientes transfundidos recebe algum procedimento terapêutico e, em muitos casos, são realizadas transfusões em pacientes que apresentam DMOS.

Descritores: transfusão de eritrócitos, unidades de terapia intensiva pediátrica, anemia, oxigenação, criança, hemoglobinas. 


\section{SUMMARY}

Mendes C. Red blood cell transfusion practice and oxygenation index in a pediatric intensive care unit. [dissertation]. São Paulo: "Faculdade de Medicina, Universidade de São Paulo"; 2007. 73p

Anemia is the primary cause of red blood cell transfusions and it is especially prevalent and even expected in critical care settings. The benefits of red blood cell transfusions include increase in tissue oxygenation, treatment of anemia and hypovolemia. There are substantial variations in transfusion practices and the optimal transfusion practice for various types of critically ill patients with anemia has not been established. Objectives To describe the clinical, hematological and therapeutic characteristics of children who received red blood cell transfusion in a Pediatric Intensive Care Unit (PICU). Methods Retrospective observational study, performed in the PICU of "Instituto da Criança", Medicine School of University of São Paulo, in 2004, with one hundred children who received red blood cell transfusion. We described the number of patients included in the study, age, reason for admission to the PICU, presence of baseline illness and multiple organ system failure (MODS), use of oxygen central venous saturation, arterial lactate, hemoglobin concentration $(\mathrm{Hb})$, hematocrit $(\mathrm{HT})$ and therapeutics procedures (mechanical ventilation, use of vasoactive drugs and renal replacement methods). Results The red blood cell transfusion occurred in $50 \%$ of the patients. Median age of patients was 18 months. The most common reason for admission was respiratory failure, in $35 \%$ of the cases. Baseline illness was present in $84 \%$ of the cases and MODS in $47 \%$ of the cases. $\mathrm{Hb}$ and $\mathrm{HT}$ were collected in all the cases and oxygen central venous saturation and arterial lactate were collected in $24 \%$ of the cases. The median pre-transfusion hemoglobin concentration was $7.8 \mathrm{~g} / \mathrm{dl}$. The patients were receiveing therapeutics procedures in $82 \%$ of the cases. Conclusions Red blood cell transfusions are performed in children of all ages. The hemoglobin concentration and hematocrit are the main reason to indicate the red blood cell transfusion. Arterial lactate and oxygen central 
venous saturation are rarely utilized. The majority of patients receive therapeutic procedures and, in many cases, patients with MODS are given red blood cell transfusions.

Descriptors: erythrocyte transfusion, pediatric intensive care units, anemia, oxygenation, child, hemoglobins. 


\section{Introdução}




\subsection{História das transfusões}

A crença de que o sangue dá e sustenta a vida e de que é capaz de salvá-la vem de tempos remotos. Existem descrições sobre as qualidades místicas do sangue desde 200 a.C. Imaginava-se que o sangue do doador traria efeitos benéficos físicos e mentais para o receptor. Os romanos costumavam beber o sangue dos gladiadores para tentar adquirir seus poderes físicos e sua coragem (Dennis et al., 1997). Foram necessários séculos de estudos e pesquisas para a ciência descobrir a real importância do sangue e dar a ele uso adequado.

A primeira complicação referente ao uso de transfusões ocorreu em 1492, quando o Papa Inocêncio VIII, portador de doença renal crônica, recebeu o sangue de três jovens rapazes para a cura de sua enfermidade. Os três doadores faleceram e não se conseguiu restabelecer a saúde do pontífice (Neto, 2005).

A doutrina de Harvey sobre circulação sanguínea foi proposta em 1616. Antes disso, não havia um conceito racional sobre transfusão de sangue. Apenas quando se desenvolveu o conceito aceitável de que o sangue circulante e o espaço intravascular poderiam ser repostos por outros fluidos 
introduzidos no corpo é que o conceito sobre transfusões de sangue surgiu (Schroeder, 1999).

As primeiras teorias e métodos sobre transfusões de sangue foram propostas e praticadas no Reino Unido e França de 1656 a 1670. A primeira ocorreu em 1665, quando foi transfundido sangue de um cachorro para outro, através de uma seringa (Kevy e Gorlin, 1998).

A primeira transfusão de sangue de um animal para um humano foi feita em 1667, em Paris, por John Baptiste-Denis (Dennis et al.,1997). Um garoto de 16 anos de idade recebeu transfusão de sangue de um cordeiro, após ter apresentado sangramentos devido a uma enfermidade. $\mathrm{O}$ garoto queixou-se de dor no braço no local da transfusão, mas não apresentou outros efeitos adversos (Kevy e Gorlin, 1998).

Baptiste-Denis continuou a fazer transfusões de animais para humanos com sucesso modesto. Seu caso mais famoso, no entanto, invalidou parte de seu trabalho. Um homem de 34 anos de idade evoluiu com convulsão e morte após ter recebido três transfusões de sangue de bezerro. Baptiste-Denis foi acusado de assassinato e processado pela viúva do paciente. No entanto, durante a investigação descobriu-se que a viúva havia envenenado o marido. Apesar de Baptiste-Denis ter sido absolvido, o parlamento francês aprovou uma lei proibindo as transfusões de sangue. Seguindo o exemplo francês, "The English Royal Medical Society" desencorajou fortemente os experimentos envolvendo transfusões. O interesse em transfusões de sangue só reapareceu na Inglaterra no início de 1800 (Kevy e Gorlin, 1998; Neto, 2005).

A primeira transfusão com sangue humano é atribuída a James Blundell, em 1818. Blundell transfundiu sangue humano em mulheres com hemorragia 
pós-parto (http://www.prosangue.sp.gov.br). Durante quase todo o século XIX o sangue foi transfundido diretamente do doador para o receptor por motivos cirúrgicos. Em 1901, o trabalho de Landsteiner delineando os grupos sanguíneos $A B O$ proveu o ímpeto inicial para os aspectos imunohematológicos da terapia transfusional. No início do século XX a transfusão como medida terapêutica ainda permanecia cheia de riscos, mas durante e logo após a Primeira Guerra Mundial o progresso tecnológico permitiu uma rápida expansão dos bancos de sangue e da transfusão de sangue como modalidade terapêutica (Galel et al., 2004).

O desenvolvimento da solução anticoagulante citrato de sódio, em 1920, permitiu a estocagem de sangue por um período superior a 10 dias. Apesar da estocagem do sangue por períodos curtos de tempo ter representado um avanço, sua aplicação não era isenta de complicações. Para surpresa dos médicos daquele tempo, um número significativo de reações hemolíticas e febre era associado ao uso do sangue estocado. Somente após 1926 é que os cientistas imaginaram que aquelas reações eram devidas à presença de bactérias pirogênicas nos equipamentos e soluções usados para conservação do sangue (Kevy e Gorlin, 1998).

A prática atual de transfusões foi inaugurada em 1958, com o desenvolvimento dos sistemas de dispositivos plásticos para a coleta e separação de sangue total em hemocomponentes. Todos os hemocomponentes e hemoderivados se originam da doação de uma unidade de sangue por um doador. No Brasil, esse processo está regulamentado pela 
portaria n. 1.376, de 19 de novembro de 1993, do Ministério da Saúde. Toda doação de sangue deve ser altruísta, voluntária e não gratificada, assim como o anonimato do doador deve ser garantido. O sangue é, portanto, um elemento precioso que depende de um ato de desprendimento do doador. Somente $1 \%$ da população brasileira doa sangue uma vez por ano, ao contrário de países europeus, aonde essa porcentagem chega a 5\% (Dorlhiac-Lhacer, 2001). $O$ ato de doação deve proteger a saúde de quem doa e de quem recebe o sangue.

A segurança do sangue depende da população na qual se faz a captação dos candidatos a doadores, de triagem clínica e sorológica, do tipo de doador (reposição versus repetição). O doador de repetição é aquele que doa mais de uma vez por ano durante vários anos seguidos. Esse doador tem um risco de transmissão de doenças muito menor que o doador de primeira vez ou o de reposição. O brasileiro geralmente não doa sangue por medo de adquirir uma doença no ato da doação ou por medo da picada da agulha, sendo o primeiro motivo muito mais freqüente que 0 segundo. Em países desenvolvidos, a grande maioria dos doadores responde que doa sangue porque viu seus pais fazê-lo. Deve existir a consciência de que a doação de sangue ajuda a salvar vidas. Na Europa, as duas grandes guerras contribuíram para amadurecer a sociedade nesse aspecto, e iniciou-se a "cultura" da doação de sangue para proteger a saúde dos compatriotas que lutavam pela pátria. Com o tempo, este ato passou a ser um hábito, passado de geração em geração e que persiste até hoje (Dorlhiac-Lhacer, 2001). 
No Brasil, podem doar sangue as pessoas sadias e que tenham entre 18 e 60 anos. A freqüência das doações é de, no mínimo, a cada dois meses para os homens e a cada três meses para as mulheres, para respeitar as necessidades e perdas de ferro. O volume retirado em cada doação é de, aproximadamente, $450 \mathrm{ml}$, não devendo exceder $13 \%$ da volemia estimada. $O$ doador deve ter $50 \mathrm{~kg}$ de peso ou mais. Todo o sangue é coletado em uma bolsa descartável e estéril, que permita o fracionamento do sangue em seus hemocomponentes. Junto à bolsa são coletadas amostras de sangue para tipagem sangüínea e sorologias (Dorlhiac-Lhacer, 2001).

As transfusões de sangue representaram uma medida de suporte essencial para 0 desenvolvimento da medicina de alta tecnologia, principalmente entre as décadas de 50 e 80 . Inovações em cirurgia cardíaca, transplantes de órgãos, tratamento de leucemia e linfomas e cuidados aos pacientes vítimas de politraumas não seriam possíveis sem a realização das transfusões de sangue. Antes da descoberta do sistema de grupos sangüíneos ABO por Landsteiner, as transfusões eram consideradas ineficazes e perigosas. Entre as décadas de 40 e 60 ficou claro que a hepatite ocorria freqüentemente em pacientes que receberam transfusões sangüíneas, e a transmissão de doenças infecciosas transformou-se na maior preocupação para os riscos de uma transfusão. Com o advento dos testes para detecção de hepatite B no sangue do doador, na década de 60 , a preocupação com as doenças infecciosas diminuiu consideravelmente, até que, na década de 80, houve o aparecimento da AIDS e esta preocupação ressurgiu (Blumberg e Heal, 1996). 


\subsection{Anemia}

Anemia é geralmente definida como a redução na massa eritrocitária ou uma concentração de hemoglobina do sangue abaixo da faixa esperada para a idade. O limite para diferenciar a anemia de um estado normal é geralmente situado em dois desvios - padrão abaixo da média para a população normal. Esta definição resulta em 2,5\% da população normal sendo classificada como anêmica. A função primária dos glóbulos vermelhos é carrear e liberar quantidades adequadas de oxigênio para os tecidos, a fim de suprir suas demandas metabólicas (Oski et al., 1998).

A concentração de hemoglobina é utilizada para definir a anemia em pacientes, de acordo com a idade e sexo (Lanzkowsky, 2000). A leitura do hematócrito e a dosagem da concentração de hemoglobina constituem padrões para determinação de uma anemia, porém esta avaliação deve ser realizada com cautela, pois os "valores normais" destes testes podem variar com a idade, sexo, estado de hidratação e altitude, sendo recomendada aos laboratórios a padronização de "valores de referência" de acordo com a região ou o tipo de população estudada (Oliveira, 1998).

A classificação das anemias pode ser fisiopatológica ou morfológica. Ambas se completam para o diagnóstico diferencial das anemias (Halsman, 2003).

De acordo com a classificação fisiopatológica existem três mecanismos fundamentais na produção de anemia: 
1- Falta ou alteração na produção de glóbulos vermelhos;

2- Excesso de destruição de glóbulos vermelhos (anemias hemolíticas);

3- Perdas hemorrágicas.

Muitas vezes, pode ocorrer mais de um destes mecanismos na produção de anemia (Oski et al., 2003).

A classificação morfológica é baseada no tamanho e na morfologia do glóbulo vermelho. As anemias são subdivididas em anemias microcíticas, normocíticas e macrocíticas (Oski et al., 2003).

A capacidade de a hemoglobina carrear oxigênio ou a afinidade da mesma pelo oxigênio é representada graficamente por uma curva sinusoidal que mostra a relação entre a saturação de hemoglobina e a pressão parcial de oxigênio $\left(\mathrm{PaO}_{2}\right)$. Esta associação é chamada de curva de dissociação da hemoglobina (Hébert et al., 2004a). A afinidade da hemoglobina pelo oxigênio pode ser alterada por várias doenças e pode desempenhar um papel significativo na resposta adaptativa à anemia (Shander, 2004).

A anemia está presente em um número substancial de pacientes com uma variedade de doenças sérias e crônicas, incluindo doenças crônicas dos rins, câncer, diabetes, doenças cardiovasculares, HIV/AIDS, artrite reumatóide e doenças da medula óssea. A anemia é a causa primária de indicação de transfusão de sangue, e pode ser aguda (ex: hemorragia) ou crônica (ex: anemia por uma doença crônica). Além disso, a anemia é especialmente prevalente e esperada em centros de terapia intensiva (Shander, 2004). Nos 
pacientes gravemente doentes, a resposta eritropoiética do organismo à anemia é dificultada devido à diminuição da disponibilidade de ferro e aos efeitos inibitórios diretos das citocinas inflamatórias. Presume-se que o risco mais significativo relacionado à anemia é o dano resultante da diminuição da capacidade de carrear oxigênio e diminuição do volume plasmático. 0 desenvolvimento de conseqüências adversas à saúde devido à anemia irá depender, em parte, da capacidade individual de cada paciente em compensar estas mudanças. A anemia, geralmente, é menos tolerada por pacientes idosos, pacientes gravemente doentes e naqueles com condições clínicas como doenças coronarianas, cerebrovasculares ou doenças respiratórias (Hébert et al., 2004b). A anemia ocorre em $36,7 \%$ das crianças gravemente doentes tratadas em centros de terapia intensiva pediátricos multidisciplinares (Desmet e Lacroix, 2004).

As características e causas de anemia em pacientes de centros de terapia intensiva são pouco estudadas. Muitos fatores obviamente contribuem e estão implicados em sua patogênese, incluindo os seguintes: a) coletas de sangue freqüentes para análises laboratoriais; b) perda de sangue pelo trato gastrointestinal, seja pela causa primária de admissão no centro de terapia intensiva ou como complicação durante a internação; c) perda de sangue por cirurgias, em particular em admissões para pós-operatório; e d) produção baixa e inapropriada de eritropoietina, o principal regulador humoral de formação de glóbulos vermelhos. Outros fatores podem influenciar a atividade eritropoiética, como a disponibilidade de ferro, vitamina B12 ou ácido fólico, assim como 
outros fatores de relativa importância que contribuem para a anemia, que ainda não foram bem determinados (Von Ahsen et al., 2001).

\subsection{Transfusões de glóbulos vermelhos}

\subsubsection{Dados epidemiológicos e diretrizes}

O "US National Center for Health Statistics" estimou que, em 1996, 3,4 milhões de americanos viviam com anemia. Uma análise descritiva dos centros de terapia intensiva de adultos dos Estados Unidos descobriu que, aproximadamente, 3500 transfusões são realizadas diariamente nos pacientes de centros de terapia intensiva, o que corresponde a aproximadamente 1,25 milhões de transfusões por ano nos centros de terapia intensiva dos Estados Unidos (Groeger et al., 1993).

Mais de 22 milhões de hemocomponentes são transfundidos a cada ano nos Estados Unidos, incluindo concentrado de glóbulos vermelhos, plasma fresco congelado, plaquetas e crioprecipitado. Muitas destas transfusões são realizadas em pacientes cirúrgicos ou obstétricos (American Society of Anesthesiologists, 1996). Foram formados vários grupos para criar diretrizes para a prática clínica de terapia de hemocomponentes, em um esforço para melhorar a prática de transfusões, diminuir a incidência de reações transfusionais adversas e diminuir custos. Nos anos 80, o "National Institutes of 
Health" realizou conferências sobre os consensos e publicou recomendações para as transfusões de glóbulos vermelhos, plaquetas e para a administração de plasma fresco congelado. Em 1984, o Colégio Americano de Ginecologistas e Obstetras também lançou recomendações para a terapia transfusional. Em 1992, o "American College of Physicians" lançou recomendações para a transfusão de glóbulos vermelhos. Em 1994, o Colégio Americano de Patologistas publicou parâmetros para a prática de transfusões de plasma fresco congelado, crioprecipitado e plaquetas. Diretrizes para a utilização de sangue foram publicadas no mesmo ano pela Associação Americana de Bancos de Sangue. Em 1996, foi publicado um artigo elaborado pela Sociedade Americana de Anestesistas, que formou uma força tarefa para criar um guideline sobre a terapia transfusional. Este artigo resumia os resultados da revisão de literatura e as recomendações da força tarefa, porém não considerou as transfusões em recém-nascidos e pacientes pediátricos. As diretrizes publicadas sobre transfusões de glóbulos vermelhos em crianças gravemente doentes são baseados em opiniões de experts ou derivadas da experiência em terapia intensiva de adultos (Armano et al., 2005).

Em julho de 2006, a Sociedade Americana de Anestesistas publicou as últimas diretrizes sobre transfusão de hemocomponentes para pacientes adultos e crianças com mais de $35 \mathrm{~kg}$, submetidos a procedimentos cirúrgicos. Foram feitas recomendações sobre a monitorização da perda sangüínea e da perfusão e oxigenação de órgãos vitais adequadas. Indicou-se transfusão de glóbulos vermelhos para pacientes com concentração de hemoglobina menor 
que $6 \mathrm{~g} / \mathrm{dl}$, especialmente para casos de anemia aguda. As transfusões de glóbulos vermelhos foram consideradas desnecessárias se a concentração de hemoglobina estiver acima de $10 \mathrm{~g} / \mathrm{dl}$. Para os casos de concentração de hemoglobina entre 6 e $10 \mathrm{~g} / \mathrm{dl}$ indicou-se avaliar a transfusão de glóbulos vermelhos na presença de isquemia de órgãos, sangramento potencial ou atual, volemia inadequada do paciente e fatores de risco para complicações devido à oxigenação inadequada (baixa reserva cardiopulmonar e alto consumo de oxigênio) (American Society of Anesthesiologists, 2006).

No Brasil, o primeiro banco de sangue surgiu no Rio de Janeiro, em 1942. A primeira legislação surgiu em 1943 e os doadores eram remunerados (em 1978, 80\% dos doadores eram remunerados). Com o surgimento da AIDS, na década de 80 , houve um processo de mudança com relação à doação e parou-se de remunerar os doadores. Em 1986, iniciou-se o teste para detecção do vírus HIV para doadores de sangue, em São Paulo. O governo federal liberou o teste para o Brasil todo apenas dois anos após (Junqueira et al, 2005).

Segundo dados da Fundação Pró-Sangue (Hemocentro de São Paulo), a cada dois segundos algum paciente necessita de transfusão de sangue, no Brasil. Cerca de uma em cada cinco pessoas internadas em um hospital necessitarão de transfusão de sangue durante o período de internação. As doações são voluntárias em $70 \%$ dos casos e de reposição em $30 \%$ dos casos. Os doadores são, em sua maioria, do sexo masculino $(60,4 \%$ das doações) e a faixa etária que mais contribui para as doações vai de 18 a 29 anos de idade (http://www.prosangue.sp.gov.br). 


\subsubsection{Indicações das transfusões}

As decisões sobre transfusões de glóbulos vermelhos geralmente são tomadas sem um completo entendimento dos benefícios e riscos das mesmas. Historicamente, os médicos assumiram que a anemia representa um risco, principalmente para pacientes com doenças cardiovasculares, e que as transfusões são benéficas para estes pacientes com anemia. Apesar de termos desenvolvido um entendimento muito mais claro sobre os riscos das transfusões de glóbulos vermelhos desde os anos 80 , os riscos da anemia e os benefícios das transfusões ainda são pouco caracterizados. Durante mais de cinco décadas, a concentração de hemoglobina de $10 \mathrm{~g} / \mathrm{dl}$ e a dosagem de hematócrito de $30 \%$ foram geralmente aceitas como os níveis mínimos tolerados, principalmente para pacientes cirúrgicos. Proposta inicialmente em 1942, a regra "10/30" foi aceita durante anos como apropriada para a indicação de transfusões de glóbulos vermelhos (Surgenor et al., 2001). Mais recentemente, no entanto, pensou-se que deveríamos abandonar as transfusões realizadas empiricamente em favor de uma prática transfusional baseada somente em necessidades fisiológicas definidas. Apesar de inúmeras recomendações, ainda existem muitas variações na prática clínica, incluindo a prática realizada em centros de terapia intensiva.

Duas questões devem ser respondidas quando consideramos o papel das transfusões de sangue no manejo do paciente gravemente doente: 
- A baixa concentração de hemoglobina é maléfica para o paciente gravemente doente?

- Se uma concentração de hemoglobina maior puder ser atingida sem risco, o paciente gravemente doente realmente será beneficiado?

A concentração de hemoglobina no sangue ou a dosagem de hematócrito isoladamente não deveriam determinar a necessidade de transfusão de glóbulos vermelhos. As indicações de transfusões deveriam basear-se também em critérios clínicos. Se a concentração de hemoglobina tem um valor limitado como guia para a necessidade de transfusões de glóbulos vermelhos, existem alternativas melhores? Através de observações informais ou estudos formais, os médicos têm tentado identificar achados clínicos que forneçam mais informações do que a concentração de hemoglobina. Sintomas como a taquicardia persistente ou taquipnéia na ausência de patologia pulmonar ou cardíaca podem refletir a inadequada oferta de oxigênio aos tecidos devido à anemia. A melhora destes sintomas após a transfusão confirma a importância destes achados (Cohen e Manno, 1998). Adaptações fisiológicas à anemia, incluindo o aumento de 2,3-DPG dos glóbulos vermelhos e o aumento do débito cardíaco, compensam um significativo número de casos de anemia crônica. A oxigenação tissular é mantida com níveis de hematócrito de $30 \%$ ou menos, desde que o volume sanguíneo permaneça normal. Estes valores são geralmente adequados em pacientes não engajados em atividades físicas vigorosas (Schroeder, 1999). Dados recentes sugerem que concentrações menores de hemoglobina são bem toleradas. Weiskopf et al. publicaram um estudo no qual promoveram a 
redução isovolêmica da concentração de hemoglobina até $5 \mathrm{~g} / \mathrm{dl}$ em pacientes saudáveis antes de cirurgias e em voluntários que não seriam submetidos a procedimentos cirúrgicos. Estes autores não acharam nenhuma evidência de redução crítica da oferta de oxigênio associada com a redução da concentração de hemoglobina (Weiskopf et al., 1998). Parece claro que a concentração de hemoglobina que cai significativamente abaixo de $10 \mathrm{~g} / \mathrm{dl}$ pode ser bem tolerada, mas não está claro que este dado pode ser aplicado aos pacientes gravemente doentes. Estes parecem não tolerar bem a anemia. Além disso, estes mesmos pacientes podem ter um risco aumentado de imunossupressão e complicações microcirculatórias por transfusões de glóbulos vermelhos.

O estudo mais recente sobre transfusões de glóbulos vermelhos em crianças foi publicado em abril deste ano, por Lacroix et al. Foram randomizados 637 pacientes estáveis gravemente doentes, que apresentavam concentrações de hemoglobina abaixo de $9,5 \mathrm{~g} / \mathrm{dl}$ nos primeiros sete dias de admissão no CTIP. Um grupo de 320 pacientes recebeu transfusão para manter a concentração de $\mathrm{Hb}$ acima de $7,0 \mathrm{~g} / \mathrm{dl}$ (estratégia restritiva) e o outro grupo, com 317 pacientes, recebeu transfusões para manter a concentração de $\mathrm{Hb}$ acima de 9,5 g/dl (estratégia liberal). Os pacientes do grupo de estratégia restritiva receberam $44 \%$ menos transfusões do que o grupo de estratégia liberal. Não houve diferenças significantes nos desfechos estudados (DMOS e taxa de mortalidade). Concluiu-se que uma estratégia restritiva de transfusões de glóbulos vermelhos pode seguramente diminuir a taxa de exposição às 
transfusões, assim como o número total de transfusões em crianças gravemente doentes, embora suspensões nas estratégias de transfusão tenham sido permitidas sob condições pré-especificadas. Recomenda-se uma estratégia restritiva de transfusões em crianças com condições clínicas estáveis internadas em CTI. No entanto, essa recomendação não se aplica a recém-nascidos prematuros, adultos idosos, pacientes com doença arterial coronariana, ou crianças com hipoxemia severa, instabilidade hemodinâmica, sangramento ativo ou doença cardíaca cianogênica (Lacroix et al, 2007).

\subsubsection{Benefícios das transfusões de glóbulos vermelhos}

Muitos conceitos de fisiologia em transporte e uso do oxigênio foram descritos na primeira parte do século XX e são aceitos até hoje. Em 1920, Barcroft observou que a oxigenação tissular dependia da concentração de hemoglobina, oxigenação do sangue pelos pulmões e débito cardíaco, para suprir adequadamente os tecidos de sangue oxigenado (Waxman, 1986).

Os benefícios das transfusões incluem aumento da oxigenação tissular, diminuição de hemorragias, tratamento da anemia e da hipovolemia. Dois estudos sugerem que a anemia aumenta o risco de morte após cirurgias em pacientes com doença cardíaca e nos gravemente doentes (Hébert et al., 1999). Existem razões para se acreditar que o metabolismo complexo e as alterações cardiovasculares dos pacientes em estado grave restringem a 
aplicabilidade de qualquer recomendação proveniente dos estudos realizados em outras populações de pacientes e em modelos experimentais, pois não existem respostas fisiológicas comparáveis entre estes grupos (Hébert et al., 1997).

A manutenção de uma concentração de hemoglobina adequada é importante para determinar uma oferta adequada de oxigênio aos tecidos. Esta oferta de oxigênio é determinada pela concentração de hemoglobina no sangue, pela saturação da hemoglobina pelo oxigênio, pelo débito cardíaco e pela eficiência com que a hemoglobina libera o oxigênio para os tecidos. A relação entre estes fatores (exceto o último) é geralmente expressa pela seguinte equação:

$$
\mathrm{DO}_{2}=\mathrm{CO}\left[(\mathrm{Hb})(\% \text { sat })(1,36)+\left(\mathrm{PaO}_{2}\right)(0,0031)\right] \text {, onde: }
$$

$\mathrm{DO}_{2}$ é a taxa de oferta de oxigênio e $\mathrm{Hb}$ é a medida da concentração de hemoglobina, \%sat é a porcentagem de saturação da hemoglobina pelo oxigênio, 1,36 representa a capacidade da hemoglobina carrear o oxigênio em um adulto humano normal (1,36 $\mathrm{ml}$ de oxigênio por grama de hemoglobina), $\mathrm{PaO}_{2}$ é a medida da pressão parcial de oxigênio no sangue, 0,0031 é o coeficiente de solubilidade do oxigênio no sangue $\left(0,0031 \mathrm{ml}\right.$ de $\mathrm{O}_{2} / 100 \mathrm{ml}$ de sangue por mmHg) e CO é o débito cardíaco (Dudell et al., 1990; Dennis et al., 1997; Shander, 2004). Desse modo, se um paciente está anêmico ou hipovolêmico, tem uma hemoglobina anormal com afinidade aumentada pelo 
oxigênio ou tem um baixo débito cardíaco, então sua oferta de oxigênio para os tecidos pode ser inadequada, mesmo na presença de uma $\mathrm{PaO}_{2}$ normal.

Idealmente, ao invés de medir a $\mathrm{PaO}_{2}$ ou a saturação arterial de hemoglobina, nós deveríamos mensurar a oferta sistêmica de $\mathrm{O}_{2}$ e o consumo de $\mathrm{O}_{2}$, simultaneamente. No entanto, esta medida é difícil de ser realizada em crianças. A saturação de hemoglobina do sangue venoso misto ou saturação venosa de oxigênio $\left(\mathrm{SvO}_{2}\right)$ está diretamente relacionada com o conteúdo de $\mathrm{O}_{2}$ no sangue que retorna dos tecidos, e pode ser mensurada em amostras de sangue retiradas de um cateter de artéria pulmonar (em adultos). Em neonatos ou crianças, a saturação no átrio direito fornece uma estimativa razoável da saturação venosa central (Dudell et al., 1990). Normalmente, a oferta de $\mathrm{O}_{2}$ é quatro a cinco vezes o consumo de $\mathrm{O}_{2}$. Desse modo, $20 \%$ a $25 \%$ da oferta de $\mathrm{O}_{2}$ é utilizada, e o restante permanece no sangue venoso. Se o sangue arterial está $100 \%$ saturado pelo $\mathrm{O}_{2}$, o sangue venoso normal estará $75 \%$ a $80 \%$ saturado. Uma queda abrupta na saturação venosa de $\mathrm{O}_{2}$ pode ser causada por uma diminuição na oferta ou um aumento no consumo (Dudell et al., 1990).

A presença de sintomas atribuídos à anemia e, presumivelmente, causados pela falha na oxigenação tissular tem sido utilizada para decidir 0 momento de se transfundir um paciente ou não. A indicação de transfusão baseia-se, geralmente, na concentração de hemoglobina do paciente. Todavia, a concentração de hemoglobina pode não ser tão importante. Esta dúvida vai de encontro à observação de que alguns pacientes toleram bem uma concentração de hemoglobina baixa sem apresentar sintomas, enquanto outros 
se tornam sintomáticos com concentrações de hemoglobina similares. A concentração de hemoglobina parece não ser um bom indicador da adequada provisão de oxigênio para os tecidos e não descreve verdadeiramente a oxigenação tissular. Existem algumas razões para isso:

1) a hemoglobina não reflete o volume do glóbulo vermelho, que poderia ser um melhor indicador para a capacidade do organismo em carrear o oxigênio;

2) a disponibilidade do oxigênio carreado pela hemoglobina depende da posição da curva de dissociação da oxi-hemoglobina, que é variável;

3) as necessidades individuais de oxigênio variam com o tempo de um organismo para outro, assim como varia a oferta do oxigênio para os tecidos;

4) é possível compensar uma baixa concentração de hemoglobina com um aumento no débito cardíaco e com ventilação adequada, e a habilidade para compensar um certo grau de anemia também depende da reserva cardiorespiratória individual;

5) a diminuição da concentração de hemoglobina durante as primeiras semanas de vida, tanto em recém nascidos pré-termo como em recémnascidos a termo, usualmente ocorre sem sintomas ou sinais de anemia ou conseqüências clínicas (Wardle e Weindling, 2001).

Um paciente pediátrico responde à anemia crônica e diminui a oferta de oxigênio para os tecidos de forma compensatória. Ocorre aumento da freqüência cardíaca, do débito cardíaco e do fluxo sanguíneo cerebral para tentar manter a oxigenação cerebral adequada. Quando estes mecanismos começam a falhar, a disponibilidade de oxigênio para os tecidos diminui. Neste 
momento, ocorre aumento na extração fracionada de oxigênio para que o consumo de oxigênio possa ser mantido. Crianças com anemia sintomática apresentam maiores medidas de extração fracionada de oxigênio quando comparadas ao grupo controle, segundo o trabalho de Wardle e Weindling (2001). As crianças com anemia assintomática têm a extração fracionada de oxigênio similar ao grupo controle. Após a transfusão, ocorre uma diminuição significativa da extração fracionada de oxigênio nas crianças sintomáticas, mas o mesmo não ocorre nos assintomáticos.

Quando a oxigenação tissular fica comprometida ocorre uma produção de lactato arterial devido ao metabolismo anaeróbico. Crianças com anemia importante apresentam altas doses de lactato arterial, com uma queda nos níveis após a transfusão de glóbulos vermelhos (Wardle e Weindling, 2001). Desta forma, a dosagem de lactato arterial, além da medida da extração fracionada de oxigênio, poderia ser um melhor guia para decidir quando uma transfusão deve ser realizada ou não.

Alguns trabalhos foram realizados nos últimos anos tentando demonstrar as mudanças que as transfusões de glóbulos vermelhos ocasionam nos pacientes com anemia. Um estudo clínico randomizado, realizado por Paul Hébert e colaboradores, em 2000, sobre o uso de transfusão de glóbulos vermelhos nos pacientes anêmicos submetidos à ventilação mecânica, não mostrou diferenças significativas na duração da ventilação mecânica nos pacientes que receberam transfusões (Hébert et al., 2001). No Canadá, foi realizado um estudo multicêntrico controlado e randomizado em 1999, que 
comparou estratégias utilizadas para a transfusão de glóbulos vermelhos (estratégia restritiva e conservadora versus estratégia liberal), para tentar descobrir se as mesmas produziam efeitos diferentes nos pacientes adultos gravemente doentes (Hébert et al., 1999). Concluiu-se, neste estudo, que a estratégia restritiva para a transfusão de glóbulos vermelhos é tão ou mais eficaz do que a estratégia liberal, com possíveis exceções nos pacientes com infarto agudo do miocárdio e angina estável.

Considerando-se a importância clínica das transfusões de glóbulos vermelhos, são notáveis os conhecimentos limitados no que diz respeito à prática de transfusões na clínica diária. Apenas poucos estudos são disponíveis para comparação entre práticas de transfusões. Os poucos estudos publicados têm demonstrado variações significativas nas práticas de transfusões de glóbulos vermelhos. Uma das revisões sobre o assunto conclui que: "Apesar das muitas deficiências na literatura clínica sobre transfusões, existem evidências substanciais sobre variações na prática médica e existência de transfusões desnecessárias" (Titlestad et al., 2001).

Estratégias mais conservadoras para a indicação de transfusões incluem como justificativas o menor risco de reações transfusionais, menor chance de transmissão de infecções, maiores reservas de sangue nos bancos de sangue e redução nos custos financeiros. 


\subsubsection{Riscos das transfusões de glóbulos vermelhos}

Os efeitos adversos das transfusões incluem transmissão de doenças infecciosas (vírus da hepatite B e C, citomegalovírus, HIV, sífilis), reações agudas hemolíticas ou não, hiperpotassemia, aloimunização, entre outros. Quando foi descoberto, em 1982, que a infecção por HIV poderia ser transmitida por transfusão de sangue, as taxas de transmissão da doença só podiam ser calculadas através do seguimento dos pacientes receptores do sangue através do tempo. Atualmente, como as taxas de transmissão de infecções virais são pequenas, são necessários modelos matemáticos para estimar o risco das transfusões de sangue. Estes modelos têm sido utilizados para estimar os riscos de transmissão de HIV, hepatite B e C e HTLV I e II, e são baseados no fato de que a transmissão da doença pode ocorrer também no período de janela imunológica (o período no qual, logo após contrair a infecção, os testes sorológicos realizados no sangue do doador ainda são negativos). Algumas estimativas indicam que o risco de infecção por HIV associado à transfusão é de 1:200.000 a 1:2.000.000 e infecção por hepatite C é de 1:30.000 a 1:150.000 (Goodnough et al., 1999). Alguns dados sugerem que a transfusão também pode ser um fator de risco para infecções nosocomiais e disfunção de múltiplos órgãos e sistemas (Laverdière et al., 2002).

Reações hemolíticas agudas e fatais após transfusão de glóbulos vermelhos também podem ocorrer, em uma taxa de 1:250.000 a 1:1.000.000 de transfusões. Aproximadamente metade das mortes por reação aguda hemolítica é causada por incompatibilidade ABO (geralmente por erro de 
administração de sangue incompatível). Além disso, 1:1.000 pacientes podem apresentar manifestações clínicas por reações transfusionais (Goodnough et al., 1999).

O microorganismo mais comumente associado à infecção bacteriana dos concentrados de glóbulos vermelhos é a Yersinia enterocolitica. Outras bactérias gram-negativas também podem ser encontradas. A contaminação bacteriana do sangue utilizado para transfusões está diretamente relacionada ao tempo de estocagem do mesmo (Goodnough et al., 1999).

Outra complicação que pode ocorrer é a lesão pulmonar aguda relacionada à transfusão. O paciente apresenta um quadro clínico caracterizado por dispnéia e hipóxia devido a um edema pulmonar de origem não cardiogênica, que pode ocorrer até quatro horas após a transfusão. A incidência atual desta reação não é bem conhecida, mas estima-se que possa ocorrer em uma freqüência de 1:5.000 transfusões (Popovsky e Moore, 1985). Acredita-se que anticorpos presentes no sangue do doador ou antígenos com especificidade para neutrófilos reagem com neutrófilos do receptor, levando a um aumento da permeabilidade da microcirculação pulmonar. A terapia é de suporte e geralmente $90 \%$ dos pacientes se recuperam.

A transfusão de glóbulos vermelhos também pode causar efeitos de imunossupressão, principalmente em mulheres multíparas ou pacientes submetidos a transplante renal. A transfusão de sangue alogênico geralmente causa aumento da regulação da imunidade humoral e diminuição da regulação da imunidade de macrófagos e células T (Blumberg e Heal, 1996). Alguns trabalhos retrospectivos e observacionais descreveram a associação entre 
exposição a sangue alogênico e recorrências precoces de câncer e aumento nas taxas de infecção em pós-operatórios (Goodnough et al., 1999).

Inúmeros são, portanto, os riscos existentes para um paciente submetido a uma transfusão de glóbulos vermelhos. Este risco só poderia ser eliminado totalmente se nenhuma transfusão fosse realizada. Existem várias sugestões para evitar que a transfusão de glóbulos vermelhos seja realizada, como o uso de colóides, eritropoietina, realização de autotransfusões, administração de ferro, ácido fólico e vitaminas aos pacientes em pré-operatórios, entre outras.

A presença de variações significativas nos índices de transfusão de glóbulos vermelhos em centros de terapia intensiva indica que o melhor momento para a indicação destas transfusões ainda não foi identificado. A indicação de transfusão de glóbulos vermelhos baseada apenas na concentração de hemoglobina e taxa de hematócrito poderia ser revista. Tendo em vista os benefícios que a redução no número de transfusões de glóbulos vermelhos poderia trazer para a prática médica é que nos sentimos incentivados a desenvolver este estudo. A adoção de critérios mais rigorosos na indicação de transfusões pode diminuir significativamente o seu número, seus efeitos adversos e a exposição a diversos doadores, resultando em benefícios para a área da saúde e redução de custos. 


\subsection{Revisão Bibliográfica}

Os levantamentos bibliográficos utilizados para a introdução e discussão foram realizados de forma manual e informatizada, sendo utilizados os seguintes descritores: transfusão de eritrócitos, unidades de terapia intensiva pediátrica, anemia, oxigenação, criança, hemoglobinas e os seguintes "descriptors": erythrocyte transfusion, pediatric intensive care units, anemia, oxygenation, child, hemoglobins. Os bancos de dados pesquisados foram Medline, Cochrane Library, Pubmed, Lilacs, Ovid. 
2. OBJETIVOS 


\subsection{Objetivo geral}

Descrever a população de crianças internadas no Centro de Terapia Intensiva Pediátrico (CTIP) do Instituto da Criança do Hospital das Clínicas da Faculdade de Medicina da Universidade de São Paulo (ICr - HCFMUSP), que recebeu transfusão de glóbulos vermelhos, em relação aos aspectos clínicos, hematológicos e terapêuticos.

\subsection{Objetivos específicos}

1- Descrever a distribuição por faixa etária das crianças transfundidas;

2- Descrever a concentração de hemoglobina e a taxa de hematócrito prétransfusão;

3- Descrever o uso de outros índices indicadores do transporte de oxigênio pré-transfusão (saturação venosa central de oxigênio e dosagem de lactato sérico arterial);

4- Descrever o quadro clínico do paciente no momento da indicação da transfusão, com relação ao uso de ventilação mecânica, drogas vasoativas, métodos de substituição renal e presença de disfunção de múltiplos órgãos e sistemas. 
3-Métodos 


\subsection{Local do estudo}

O Instituto da Criança (ICr) do Hospital das Clínicas da Faculdade de Medicina da Universidade de São Paulo foi inaugurado em 1976. Atende crianças e adolescentes de 0 a 19 anos através de 21 especialidades médicas e é um hospital de nível terciário e de ensino.

O estudo foi realizado em pacientes admitidos no Centro de Terapia Intensiva Pediátrica do ICr, que possui 13 leitos. São internados em torno de 450 pacientes por ano (média de 37 pacientes por mês). $O$ índice médio de ocupação é de $98,6 \%{ }^{1}$

Por tratar-se de hospital pediátrico de nível terciário, a maioria das crianças admitidas apresenta uma doença de base já diagnosticada ou em investigação.

\footnotetext{
${ }^{1}$ Informações fornecidas pelo Serviço de Arquivo Médico e Estatística do $\mathrm{ICr}$ - 2006.
} 


\subsection{Delineamento do estudo}

Estudo retrospectivo observacional de pacientes da faixa etária pediátrica (um mês a 18 anos) internados em um centro de terapia intensiva de um hospital universitário, que receberam transfusão de glóbulos vermelhos, num período de seis meses (março a setembro de 2004).

\subsection{População estudada}

\subsubsection{Critérios de inclusão}

- Crianças internadas no CTIP do ICr - HCFMUSP no período de março a setembro de 2004, que receberam transfusão de glóbulos vermelhos;

- Crianças com idade entre 29 dias de vida e 18 anos incompletos.

\subsubsection{Critérios de exclusão}

- Recém-nascidos e crianças maiores de 18 anos;

- Recusa, por qualquer motivo, de receber transfusão sangüínea.

O tamanho amostral não foi calculado por tratar-se de um estudo descritivo. Foi escolhida uma amostra de conveniência e colhidos os dados dos pacientes internados no período estipulado. 


\subsection{Descrição dos dados coletados}

Os dados coletados foram registrados em uma ficha de admissão. (Quadro 1)

\section{Quadro 1 - Ficha de admissão}

Nome:

Caso № :

Hospital:

Idade:

Registro:

Data de nascimento:

Data de internação:

Motivo da internação no CTI:

Doença de base: Não Sim - Subespecialidade:

- Diagnóstico de base:

DMOS: Não

Sim Sistemas acometidos: cardiovascular hematológico respiratório renal neurológico

$\mathrm{SaO}_{2}$ (oxímetro de pulso ou gasometria arterial): $\%$

$\mathrm{SvO}_{2}$ (gasometria venosa central): $\%$

Concentração de $\mathrm{Hb}$ : g/dl Taxa de HT: Lactato sérico:

Procedimentos terapêuticos: ventilação mecânica drogas vasoativas hemodiálise diálise peritoneal hemofiltração

DMOS: Disfunção de múltiplos órgãos e sistemas $\mathrm{Hb}=$ hemoglobina $\mathrm{HT}=$ hematócrito
$\mathrm{SaO}_{2}=$ saturação arterial de oxigênio $\mathrm{SvO}_{2}=$ saturação venosa de oxigênio 
Descrevemos a população estudada de acordo com os seguintes critérios:

- Número de pacientes;

- Faixa etária (em meses);

- Motivo da internação no CTIP: diagnóstico clínico à admissão;

- Doença de base: presença ou ausência e, se presente, qual a subespecialidade ambulatorial;

Número de disfunções orgânicas: baseado nos critérios preconizados por Wilkinson et al., 1986. Apesar de Wilkinson et al. utilizarem o termo "falência orgânica", optou-se neste estudo pela utilização do termo "disfunção", que vem sendo preconizado nos últimos anos e parece representar melhor a seqüência descritiva das mudanças contínuas que ocorrem nos sistemas orgânicos após uma agressão. $\mathrm{O}$ termo "disfunção" é capaz de descrever desde a perda total da função de um órgão até um processo de deterioração dessa mesma função, sem que tenha ocorrido, necessariamente, a perda total da mesma (Beal e Cerra, 1994). Consideramos DMOS a presença de duas ou mais disfunções orgânicas concomitantes; (Anexo A)

$\mathrm{SvO}_{2}, \mathrm{SaO}_{2}$ e lactato sérico: se foram coletados ou não e quais os valores;

- Concentração de hemoglobina e taxa de hematócrito: se foram coletados ou não e quais os valores;

- Procedimentos terapêuticos (uso de ventilação mecânica, uso de drogas vasoativas ou métodos de substituição renal - diálise peritoneal, hemodiálise, hemofiltração). 
As variáveis $D M O S$ e procedimentos terapêuticos foram coletadas no momento da indicação da transfusão.

Para as variáveis $\mathrm{SvO}_{2}, \mathrm{SaO}_{2}$, lactato sérico, concentração de hemoglobina e taxa de hematócrito pré-transfusionais foram considerados os últimos valores verificados pelos exames laboratoriais realizados até 24 horas antes de cada evento de transfusão.

Cada transfusão de glóbulos vermelhos prescrita foi considerada como um novo evento, mesmo que tenham ocorrido várias transfusões em um mesmo paciente.

A análise das variáveis faixa etária, motivo de internação no CTIP, doença de base e subespecialidade foi realizada no total de pacientes transfundidos. A análise das variáveis $\mathrm{DMOS} \mathrm{SvO}_{2}, \mathrm{SaO}_{2}$, lactato sérico, concentração de hemoglobina, taxa de hematócrito e procedimentos terapêuticos foi realizada no total de eventos transfusionais.

Os valores de hemoglobina pré-transfusional foram divididos em três categorias: valores menores ou iguais a 7,0 g/dl, entre 7,1 e 9,9 g/dl e maiores ou iguais a $10 \mathrm{~g} / \mathrm{dl}$, de acordo com patamares estudados por outros autores (Hébert et al., 1999). 


\subsection{Análise estatística}

Os dados foram armazenados em bancos de dados criados nos softwares "Access" e "Excel". As variáveis categóricas foram expressas em valores absolutos e percentuais. Para a descrição das variáveis contínuas foram utilizados os cálculos de mediana, intervalo de variação e limites mínimo e máximo. Os cálculos foram realizados no software Statistical Package for Social Sciences (S.P.S.S.) versão 13.0. Os cálculos de intervalo de confiança foram realizados utilizando o software "GraphPad StatMate” (versão 1.01).

\subsection{Aspectos éticos}

O projeto foi aprovado pela Comissão de Ética para Análise de Projetos de Pesquisa - CAPPesq da Diretoria Clínica do Hospital das Clínicas e da Faculdade de Medicina da Universidade de São Paulo, em sessão de 12/11/03 (Protocolo de Pesquisa no 737/03). (ANEXO B)

Como o estudo era observacional e previa apenas a análise de prontuários, sem nenhum tipo de intervenção diagnóstica e/ou terapêutica, não utilizamos o "Termo de Consentimento Livre e Esclarecido". Comprometemonos a manter sigilo absoluto com relação aos dados colhidos. 
4- Resultados 


\subsection{População estudada}

Foram internados 201 pacientes no período de seis meses descrito (março a setembro de 2004). Do total de pacientes internados, $11 \%$ dos prontuários não foram encontrados (23 de 201 prontuários). Quatro pacientes (2\%) foram excluídos do estudo devido à idade, conforme os critérios de exclusão. A transfusão de glóbulos vermelhos foi realizada em $50 \%$ dos pacientes (100 de 201 pacientes) e em 37\% dos pacientes internados (74 de 201 pacientes) não foram realizadas transfusões. (Gráfico 1)

\section{Gráfico 1- Total de pacientes internados no CTIP no período do estudo}

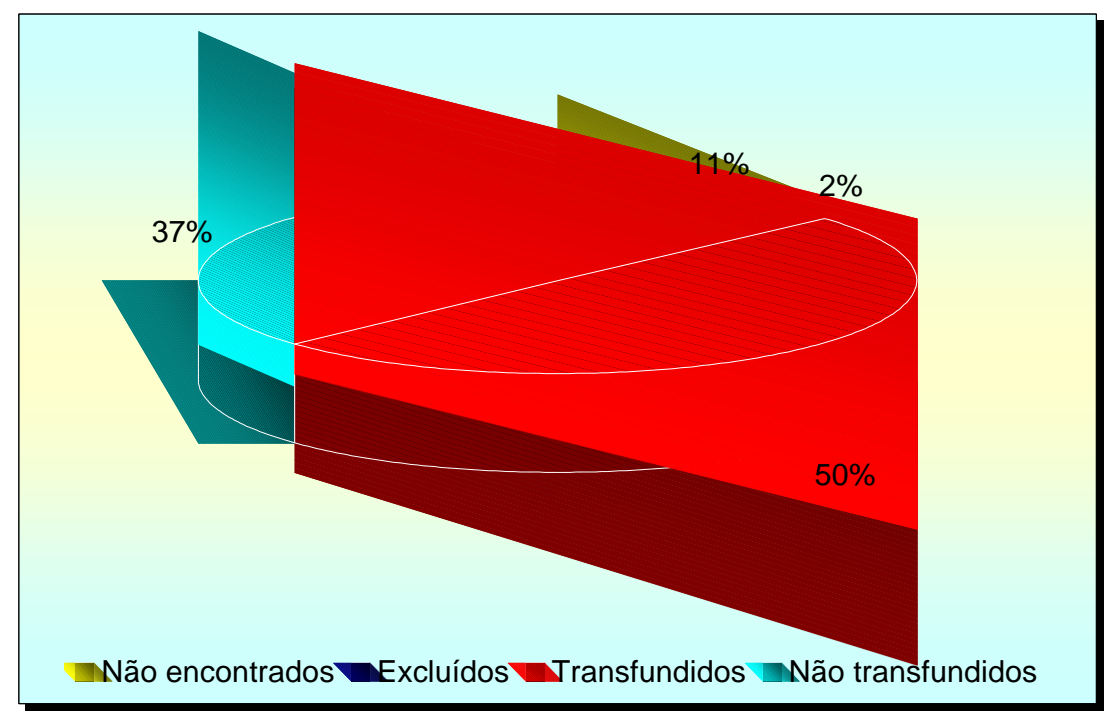




\subsection{Pacientes transfundidos}

As características dos pacientes transfundidos estão descritas na tabela 1. Os diagnósticos de internação no CTIP mais freqüentes foram insuficiência respiratória aguda em 35\% dos casos (35 de 100 pacientes), pós-operatório em $17 \%$ dos casos (17 de 100 pacientes) e choque séptico em 14\% dos casos (14 de 100 pacientes). Em alguns pacientes os diagnósticos estavam associados.

Tabela 1 - Características dos pacientes transfundidos

\begin{tabular}{lc}
\hline & Transfundidos \\
\hline Pacientes, $\boldsymbol{n}$ & 100 \\
\hline Idade, meses, mediana (variação) & \\
\hline Motivo da internação no CTIP, $\boldsymbol{n}$ (\%) & $35(35)$ \\
\hline Insuficiência respiratória aguda & $17(17)$ \\
\hline Pós-operatório & $14(14)$ \\
\hline Choque séptico & $9(9)$ \\
\hline Sepse / Sepse grave & $4(4)$ \\
\hline Hemorragia digestiva alta & $3(3)$ \\
\hline Coma / Rebaixamento do nível de consciência & $2(2)$ \\
\hline Emergência hipertensiva & $2(2)$ \\
\hline Choque hemorrágico / hipovolêmico & $2(2)$ \\
\hline Insuficiência renal aguda & $2(2)$ \\
\hline Acidente vascular cerebral & $2(2)$ \\
\hline Arritmia cardíaca & $2(2)$ \\
\hline Apnéia / Broncoespasmo & \\
\hline Outros & \\
\hline
\end{tabular}


Doença de base estava presente em $84 \%$ dos casos ( 84 de 100 pacientes), sendo mais freqüentes as doenças oncohematológicas (21\% dos casos), seguido de atresia de vias biliares em $8 \%$ dos casos. Os pacientes foram atendidos por médicos de diversas especialidades, sendo as mais freqüentes oncologia ( $20 \%$ dos casos), cirurgia pediátrica ( $15 \%$ dos casos) e hepatologia ( $9 \%$ dos casos). (Tabela 2$)$

Tabela 2 - Distribuição dos pacientes por doença de base e especialidade médica

\begin{tabular}{lc}
\hline & Transfundidos \\
\hline Pacientes, $\boldsymbol{n}$ & 100 \\
\hline Doença de base, $\boldsymbol{n}$ (\%) & $84(84)$ \\
\hline Especialidade médica, $\boldsymbol{n}(\%)$ & \\
\hline Oncologia & $20(20)$ \\
\hline Cirurgia Pediátrica & $15(15)$ \\
\hline Hepatologia & $9(9)$ \\
\hline Neurologia & $8(8)$ \\
\hline Cardiologia & $7(7)$ \\
\hline Nefrologia & $5(5)$ \\
\hline Imunologia & $4(4)$ \\
\hline Infectologia & $4(4)$ \\
\hline Pneumologia & $3(3)$ \\
\hline Neurocirurgia & $3(3)$ \\
\hline Genética & $2(2)$ \\
\hline Hematologia & $1(1)$ \\
\hline Endocrinologia & $1(1)$ \\
\hline Gastroenterologia & $1(1)$ \\
\hline Reumatologia & $1(1)$ \\
\hline Sem especialidade & $16(16)$ \\
\hline
\end{tabular}




\section{3 - Eventos transfusionais}

Ocorreram 173 eventos transfusionais no grupo de 100 pacientes transfundidos.

A presença de disfunção de múltiplos órgãos e sistemas (DMOS) foi constatada em $47 \%$ dos eventos transfusionais (80 de 173 eventos). Ocorreram disfunções de dois sistemas em 34\% dos eventos (58 de 173 eventos transfusionais) e de três sistemas em 12\% dos eventos (21 de 173 eventos transfusionais). Não houve casos de disfunção em cinco sistemas. (Gráfico 2)

\section{Gráfico 2- Disfunção de múltiplos órgãos nos eventos transfusionais}

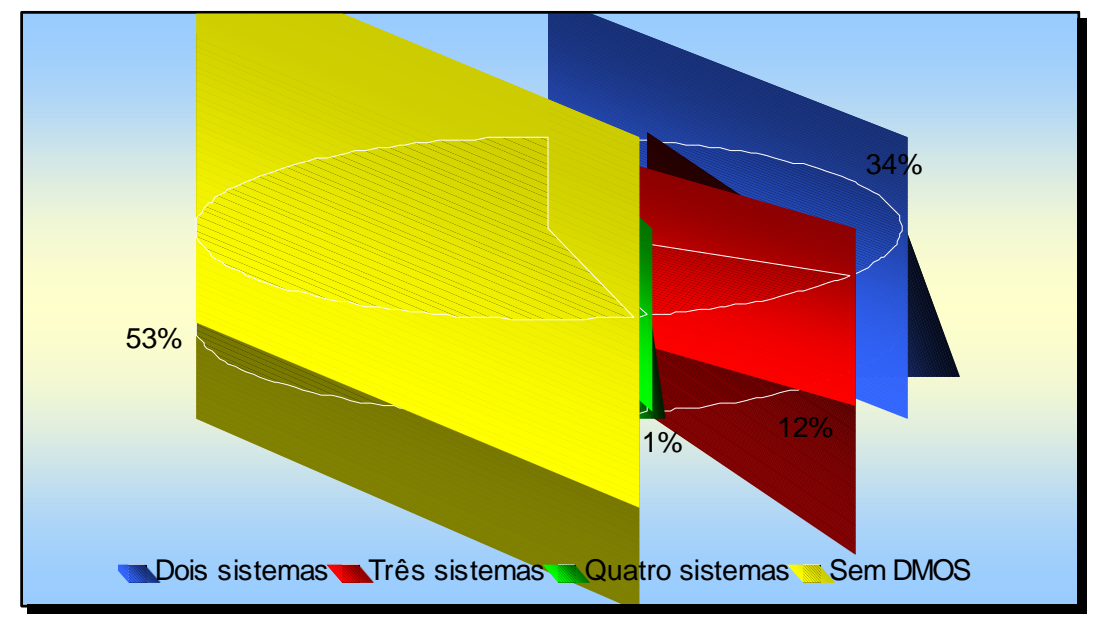

Ocorreu disfunção do sistema respiratório em 36\% dos eventos transfusionais (62 de 173 eventos transfusionais) e do sistema cardiovascular em 32,9\% dos eventos (57 de 173 eventos transfusionais). (Tabela 3) 
Tabela 3 - Sistemas mais acometidos por disfunção nos eventos transfusionais

\begin{tabular}{lccl}
\hline \multicolumn{1}{c}{ Sistema } & $\mathbf{N}$ & $\%$ & (IC 95\%) $^{\star}$ \\
\hline Respiratório & 62 & 35,8 & $(28,6-43,4)$ \\
\hline Cardiovascular & 57 & 32,9 & $(26-40,5)$ \\
& & & \\
\hline Hematológico & 46 & 26,5 & $(20,1-33,7)$ \\
\hline Renal & 14 & 8,0 & $(4,5-13,2)$ \\
\hline Neurológico & 4 & 2,3 & $(0,6-5,8)$ \\
\hline & & & \\
${ }^{\prime}$ IC 95\%, intervalo de confiança de 95\% &
\end{tabular}

A concentração de hemoglobina e taxa de hematócrito foram colhidos em 172 eventos transfusionais (99,4\%). Apenas em um caso foi realizada transfusão de glóbulos vermelhos sem a dosagem dos mesmos.

A saturação arterial de oxigênio foi verificada em todos os casos.

A saturação venosa de oxigênio e o lactato sérico arterial foram coletados em 14\% dos casos (24 de 173 eventos transfusionais). (Gráfico 3)

\section{Gráfico 3 - Variáveis coletadas nos eventos transfusionais}

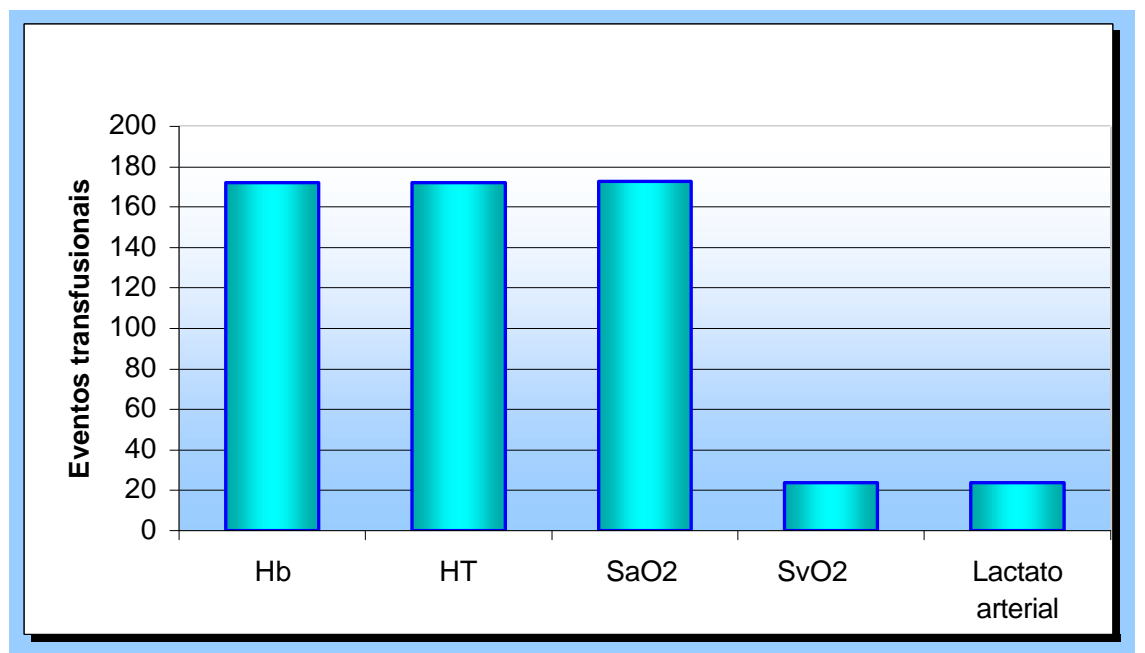


As variáveis contínuas coletadas antes da transfusão de glóbulos vermelhos estão descritas na tabela 4. As distribuições destas variáveis resultaram assimétricas (teste de Kolmogorov - Smirnov) e, por isso, os resultados foram descritos através de mediana e intervalo de variação.

Tabela 4 - Variáveis coletadas antes dos eventos transfusionais

\begin{tabular}{lcccc}
\hline & Mediana & Mínimo & Máximo & Intervalo de variação \\
\hline $\mathrm{Hb}(\mathrm{g} / \mathrm{dl})$ & 7,8 & 3,2 & 12,5 & 9,3 \\
\hline $\mathrm{HT}(\%)$ & 23,0 & 10,7 & 35,0 & 24,3 \\
\hline $\mathrm{SaO}_{2}(\%)$ & 98,0 & 78,0 & 100,0 & 22,0 \\
\hline $\mathrm{SvO}_{2}(\%)$ & 73,7 & 42,3 & 92,0 & 49,7 \\
\hline Lactato arterial $(\mathrm{mg} / \mathrm{dl})$ & 7,1 & 1,3 & 35,0 & 33,7 \\
\hline
\end{tabular}

A freqüência de eventos transfusionais variou conforme os valores de concentração de hemoglobina, como podemos verificar na tabela 5.

Tabela 5 - Freqüência de eventos transfusionais segundo a concentração de hemoglobina.

\begin{tabular}{cc}
\hline $\mathbf{H b}(\mathbf{g} / \mathbf{d l})$ & Eventos transfusionais, $\mathbf{n}(\%)$ \\
\hline$=7,0$ & $37,0(21,4)$ \\
\hline $7,1-9,9$ & $131,0(75,7)$ \\
\hline$=10$ & $4,0(2,3)$ \\
\hline Não colhido & $1,0(0,6)$ \\
\hline Total & $173,0(100)$ \\
\hline
\end{tabular}


No momento da indicação da transfusão, 82\% (142 de 173 eventos transfusionais) estavam sendo submetidos a algum procedimento terapêutico (ventilação mecânica, métodos de substituição renal e/ou uso de drogas vasoativas). (Tabela 6$)$

Tabela 6 - Freqüência de uso de procedimentos terapêuticos no momento da indicação da transfusão de glóbulos vermelhos

\begin{tabular}{lccl}
\hline Procedimento terapêutico & $\boldsymbol{N}$ & $\%$ & (IC 95\%) $^{*}$ \\
\hline Ventilação mecânica & 122 & 70,5 & $(63,1-77,1)$ \\
\hline Drogas vasoativas & 70 & 40,4 & $(33,0-48,1)$ \\
\hline Diálise peritoneal & 17 & 9,8 & $(5,8-15,2)$ \\
& & & \\
\hline Hemofiltração & 4 & 2,3 & $(0,6-5,8)$ \\
\hline Hemodiálise & 1 & 0,5 & $(0,01-3,1)$ \\
\hline${ }^{*}$ C 95\%, intervalo de confiança de 95\% & & &
\end{tabular}


5. Discussão 
A transfusão de glóbulos vermelhos ocorre com freqüência em pacientes internados em centros de terapia intensiva. O principal critério para a indicação da mesma é a dosagem da concentração de hemoglobina e taxa de hematócrito.

\subsection{Sobre os métodos}

Escolhemos o centro de terapia intensiva pediátrica do Instituto da Criança para a realização do estudo por tratar-se de um CTI de hospital terciário, com grande número de leitos, com pacientes de diversas faixas etárias e diferentes diagnósticos à admissão (diagnósticos clínicos e cirúrgicos).

Optamos pela realização de um estudo observacional e retrospectivo, através da análise dos prontuários médicos, que não interferisse na prática diária da equipe médica. Desta forma, pudemos observar o que realmente ocorria no centro de terapia intensiva pediátrico, sem que o estudo influenciasse a decisão da equipe médica em realizar ou não a transfusão de glóbulos vermelhos.

Incluímos crianças de praticamente todas as idades no estudo, tentando, desta forma, observar se há alguma variação na indicação da transfusão de glóbulos vermelhos de acordo com a faixa etária ou não. 
Todas as crianças internadas no período do estudo poderiam estar aptas a participar do mesmo, desde que obedecessem aos critérios de inclusão e exclusão. Poucos foram os casos de pacientes excluídos do estudo ( $2 \%$ dos casos).

Não foi realizado cálculo do tamanho da amostra estudada, pois, como o estudo era descritivo, a amostra foi a de conveniência. Foram colhidos os dados dos pacientes internados no período estipulado.

Utilizamos os prontuários dos pacientes internados e a dificuldade para análise dos mesmos ocorreu por problemas variados, como a ausência de anotações dos dados dos pacientes ou anotações incompletas, dificuldade em localização dos prontuários dos pacientes que receberam alta do CTI pediátrico, encaminhamento dos prontuários para o serviço de arquivo médico ou para outros setores do hospital (setor de convênio ou faturamento, por exemplo).

Uma limitação do nosso estudo foi que, por algumas vezes, ocorreram anotações incompletas no prontuário no momento imediatamente anterior à indicação da transfusão, levando-nos a procurar as causas de indicação da mesma através dos exames laboratoriais daquele dia determinado. Estes dados poderiam não traduzir, de maneira explícita, a razão pela qual a equipe médica optou por realizar a transfusão de glóbulos vermelhos naquele paciente, naquele exato momento.

Todos os dados foram anotados em uma ficha de admissão, que compreendia as diversas informações necessárias para o desenvolvimento do estudo. Os prontuários foram analisados criteriosamente, para que nenhum evento de transfusão passasse despercebido e não fosse incluído no estudo. 
Durante o período de março a setembro de 2004, 201 pacientes foram internados, sendo que $50 \%$ deles (100 pacientes) receberam transfusão de glóbulos vermelhos. Setenta e quatro pacientes (37\% dos casos) não receberam transfusão, 23 pacientes (11\% dos casos) não tiveram seus prontuários localizados (já haviam recebido alta do CTI e o prontuário não foi localizado no arquivo médico - SAME) e quatro pacientes foram excluídos do estudo ( $2 \%$ dos casos).

Identificamos 23 pacientes com prontuários que não foram analisados, por não terem sido localizados. Uma análise dos dados de internação e das fichas de admissão desses pacientes, preenchidas pelos médicos residentes do CTIP durante a internação, nos permitiu observar que, provavelmente, 15 pacientes não receberam transfusão de glóbulos vermelhos. Desta forma, ocorreu perda de seguimento em apenas oito pacientes (receberam transfusão de glóbulos vermelhos, mas não foram incluídos no estudo). No entanto, não computamos os dados dos oito pacientes ao total de pacientes incluídos no estudo, pois não poderíamos comprovar a veracidade das informações preenchidas na ficha de internação, já que o prontuário não foi localizado.

Para análise da presença de disfunção de múltiplos órgãos e sistemas utilizamos os critérios de Wilkinson (Wilkinson et al, 1986). Apesar dos critérios de Wilkinson serem mais antigos do que outros critérios descritos para análise de DMOS, optamos por sua utilização porque estes critérios podem ser utilizados retrospectivamente, e nosso estudo trata-se de uma análise retrospectiva. Não utilizamos o escore "Paediatric Logistic Organ Dysfunction" (PELOD), por exemplo, pois se trata de um escore prospectivo, que é aplicado durante todo o período de internação da criança no CTI (Leteurtre et al., 2003). 
Outra limitação do nosso estudo foi que a coleta de dados foi realizada em um período de até 24 horas antes da indicação da transfusão de glóbulos vermelhos. Talvez esse tempo de coleta tenha sido relativamente grande, pois existem variáveis que podem mudar de maneira significativa e rápida, como a saturação venosa central de oxigênio, por exemplo. Sugerimos que, num próximo estudo prospectivo, restrinja-se o intervalo de tempo entre a indicação da transfusão e a coleta dos dados.

A análise de pacientes e eventos transfusionais foi realizada de maneira separada porque consideramos que existem variáveis que não se modificam ou se modificam pouco durante o período de internação, como a doença de base e a idade, por exemplo. Para estes casos, analisamos os pacientes transfundidos. As variáveis que se modificam com freqüência durante a internação, como a $\mathrm{SvO}_{2}$ e a concentração de hemoglobina, por exemplo, foram analisadas no grupo de eventos transfusionais.

\subsection{Sobre os resultados}

\subsubsection{População estudada}

Dentre os 201 pacientes internados no período do estudo, 100 pacientes ( $50 \%$ dos pacientes) receberam transfusão de glóbulos vermelhos e puderam ser incluídos no estudo. Comparando nosso estudo com outros realizados em crianças, vemos que as amostras estudadas incluíram número semelhante de pacientes. Dentre os estudos realizados em centros de terapia intensiva pediátricos, podemos citar um que analisou 240 crianças, das quais $54,6 \%$

(131 de 240 crianças) foram transfundidas (Goodman et al., 2003). Outro estudo, realizado em crianças, incluiu 985 pacientes, dos quais 139 receberam 
transfusão de glóbulos vermelhos (14\% dos pacientes) e 846 pacientes não foram transfundidos (Armano et al., 2005). No Brasil, há um estudo que mostra incidência de transfusão de glóbulos vermelhos de 23,3\% (144 de 617 pacientes), realizado em um CTI pediátrico de um hospital universitário (Reis et al., 2006). Nossa incidência de transfusão de glóbulos vermelhos de $50 \%$ pode ser devido ao grande número de pacientes com doenças de base prévias, com maior probabilidade de anemia já desenvolvida no período anterior ao da internação em nosso CTI, e à gravidade de nossos casos internados, já que pacientes gravemente doentes têm maior chance de desenvolver anemia durante o período de internação.

Apesar de termos analisado praticamente todos os pacientes que receberam transfusão, essa é uma amostra relativamente pequena quando comparada com estudos realizados em adultos, que também analisaram a incidência de transfusões em centros de terapia intensiva. No estudo "CRIT", que analisou a incidência de anemia e de transfusões de sangue em pacientes adultos graves, realizado por Corwin et al., em 2004, participaram 284 centros de terapia intensiva e foram analisados 4892 pacientes, sendo que $44 \%$ dos pacientes receberam transfusão. Outro estudo (“ $A B C$ Trial'), realizado em adultos, incluiu 3534 pacientes, de 146 centros de terapia intensiva na Europa, constatando uma freqüência de transfusões em 37\% dos casos (1307 de 3534 pacientes) (Vincent et al., 2002). No Brasil, um estudo realizado por Ferreira et al., em pacientes adultos de um hospital universitário, mostrou que, do total de 654 pacientes analisados, 108 (16,5\% dos pacientes) receberam transfusão de glóbulos vermelhos (Ferreira et al., 2005).

Em um estudo realizado no Canadá, que incluiu 41.568 pacientes 
adultos, admitidos em 11 hospitais daquele país, 25.811 pacientes foram admitidos em centros de terapia intensiva e receberam transfusões. A taxa de transfusão de glóbulos vermelhos variou de 23,8 a 51,9\% (Hutton et al., 2005).

\subsubsection{Pacientes transfundidos}

Nosso estudo mostrou que a idade mediana dos pacientes que receberam transfusão de glóbulos vermelhos foi de 18 meses. A idade média dos pacientes transfundidos em estudos semelhantes foi de $20,3 \pm 35,6$ meses (Reis MA et al., 2006), 6,0 $\pm 5,9$ anos (Armano et al., 2005) e 6,5 anos (Goodman et al., 2003).

Os motivos de internação em um CTI variam, geralmente, de acordo com a complexidade dos casos atendidos naquele hospital. Em nosso estudo, o motivo de internação no CTIP mais freqüente foi insuficiência respiratória aguda em 35\% dos casos (35 de 100 pacientes). Como há um grande número de cirurgias realizadas no $\mathrm{ICr}$, pós-operatório foi o segundo motivo mais freqüente à internação dos pacientes no CTI. O estudo realizado por Armano et al, em 2005, descreve, como motivos de internação mais freqüentes, a insuficiência respiratória (57,9\% dos casos) e as cirurgias cardíacas eletivas (38,1\% dos casos). Já no estudo realizado por Goodman et al., em 2003, os principais motivos de internação no CTI foram as afecções ortopédicas (22,1\% dos casos), seguido de doenças de origem infecciosa (16,8\% dos casos). Ambos são estudos realizados em crianças. Em adultos, o principal motivo de internação no CTI foi o pós-operatório de cirurgias eletivas, em $41,9 \%$ dos casos, no estudo realizado por Vincent et al., em 2002. O mesmo ocorreu no estudo de Ferreira et al., onde $27,7 \%$ dos pacientes eram oriundos das 
unidades de centro cirúrgico, seguidos de $22,2 \%$ oriundos das unidades de emergência e 20,3\% da clínica médica (Ferreira et al., 2005).

A presença de um número alto de pacientes com doença de base em nosso estudo (84\% dos casos) deveu-se, principalmente, ao fato de que nosso CTI localiza-se em um hospital de nível terciário, referência em tratamento de doenças raras e complexas em nosso país, para onde são encaminhados pacientes que, na maioria das vezes, possuem doenças prévias à internação no CTI.

Como um quinto dos pacientes incluídos no estudo apresentavam doenças oncológicas ( $20 \%$ dos casos), que sabidamente cursam com anemia, pode ser esta uma das explicações para o fato de termos encontrado um alto número de transfusões de glóbulos vermelhos (50\% dos pacientes internados foram transfundidos).

\subsection{3 - Eventos transfusionais}

Pacientes internados em CTI com freqüência recebem mais de uma transfusão ao longo de todo o período de internação. No estudo "CRIT", realizado nos Estados Unidos, 44\% dos pacientes receberam uma ou mais transfusões de glóbulos vermelhos (média de 4,6 $\pm 4,9$ unidades) (Corwin et al., 2004). Em nosso estudo, foram 173 eventos transfusionais para 100 pacientes transfundidos. As transfusões de glóbulos vermelhos são freqüentemente utilizadas para tratamento da anemia em pacientes graves, resultando em alto uso de transfusões de glóbulos vermelhos no CTI. A porcentagem de pacientes transfundidos nos centros de terapia intensiva de 
adultos é inversamente relacionada à concentração de hemoglobina à admissão e diretamente relacionada à idade do paciente e gravidade da doença (Napolitano, 2004).

A disfunção de múltiplos órgãos e sistemas (DMOS) é mais comum do que a morte em pacientes graves internados em centros de terapia intensiva pediátricos. Sua incidência varia de 11 a $27 \%$, de acordo com os trabalhos publicados (Proulx et al., 1994; Proulx et al., 1996; Wilkinson et al., 1986; Wilkinson et al., 1987). Estudo prévio sobre DMOS, realizado em nosso CTI por Kalil Filho et al., em 1995, demonstrou uma incidência em $60 \%$ dos casos, sendo que os dois sistemas mais acometidos foram o sistema respiratório (52\% dos casos) e o sistema cardiovascular ( $50 \%$ dos casos).

A presença de DMOS aumenta o número de transfusões de glóbulos vermelhos realizadas, assim como a presença de anemia, doença cardíaca e doença grave (Armano et al., 2005). Encontramos, em nosso estudo, uma incidência de $47 \%$ de DMOS nos eventos transfusionais (80 de 173 eventos), sendo disfunções de dois sistemas em 34\% dos eventos (58 de 173 eventos transfusionais) e de três sistemas em 12\% dos eventos (21 de 173 eventos transfusionais). No estudo realizado por Lacroix et al., ocorreu DMOS (segundo os critérios de Prouxl et al., 1996) em 33\% dos pacientes do grupo de estratégia restritiva e em $34 \%$ dos pacientes do grupo de estratégia liberal. A disfunção do sistema respiratório foi a mais encontrada, em $73 \%$ e $78 \%$ dos pacientes dos dois grupos, respectivamente (Lacroix et al., 2007). Em nosso estudo a disfunção do sistema respiratório também foi a mais encontrada, em $35,8 \%$ dos eventos transfusionais.

A concentração de hemoglobina e a taxa de hematócrito são os 
principais parâmetros utilizados para a indicação de uma transfusão de glóbulos vermelhos. Recomendações prévias sobre transfusões sugeriam que a transfusão era raramente indicada quando a concentração de hemoglobina estava acima de $10 \mathrm{~g} / \mathrm{dL}$, mas que deveria ser realizada quando a concentração de hemoglobina caísse abaixo deste valor (Shorr e Jackson, 2005). No entanto, estas recomendações eram mais por conservadorismo do que por resultados de estudos clínicos. Esta lacuna de dados mais evidentes resulta em variações na prática médica e, certamente, explica a freqüência elevada de transfusões de glóbulos vermelhos em centros de terapia intensiva. O estudo canadense realizado por Hébert et al., em 1998, revelou que muitos médicos intensivistas realizam transfusões de glóbulos vermelhos quando a concentração de hemoglobina do paciente adulto está, aproximadamente, em 9 g/dL. O estudo observacional realizado na Europa, em 2002, com 3534 pacientes adultos, mostrou que a média de concentração de hemoglobina prétransfusional era de 8,4 g/dL (Vincent et al., 2002). Estudo similar, realizado no Reino Unido, confirmou estas observações (Rao et al., 2002). Nesses estudos, a principal razão para justificar a transfusão foi "baixa concentração de hemoglobina".

Existem poucos estudos realizados em faixas etárias pediátricas (a maioria dos estudos publicados foi realizada em adultos ou recém-nascidos). Em nosso estudo, a mediana de concentração de hemoglobina prétransfusional foi de $7,8 \mathrm{~g} / \mathrm{dL}$. A grande maioria das transfusões foram realizadas com $\mathrm{Hb}$ entre $7,1-9,9 \mathrm{~g} / \mathrm{dL}$ (75,7\% dos eventos transfusionais), seguido de transfusões realizadas com $\mathrm{Hb}$ menor ou igual a $7,0 \mathrm{~g} / \mathrm{dL}(21,4 \%$ dos eventos transfusionais). Levando-se em conta uma estratégia restritiva de 
transfusão de glóbulos vermelhos, observamos que pode ter havido grande número de transfusões desnecessárias.

Podemos ver na tabela 7 a comparação entre os valores de hemoglobina pré-transfusional nos vários estudos realizados, tanto em crianças como em adultos.

Tabela 7- Comparação entre valores de Hb pré-transfusional nos diversos estudos

\begin{tabular}{|c|c|c|}
\hline Estudo & $\begin{array}{l}\text { Faixa etária da } \\
\text { população estudada }\end{array}$ & $\begin{array}{c}\text { Hb pré-transfusional } \\
(\mathrm{g} / \mathrm{dL})\end{array}$ \\
\hline Hébert et al., 1997 & Adultos & $8,1 \pm 0,1$ \\
\hline Hébert et al., 1998 (TRICC) & Adultos & $8,6 \pm 1,3$ \\
\hline Cassut et al., 1999 & Adultos & $8,1 \pm 0,1$ \\
\hline Rao et al., 2002 & Adultos & $8,5 \pm 1,4$ \\
\hline Vincent et al., 2002 (ABC Trial) & Adultos & $8,4 \pm 1,3$ \\
\hline Corwin et al., 2004 (CRIT study) & Adultos & $8,6 \pm 1,7$ \\
\hline Mazza et al., 2005 & Adultos & $8,1 \pm 0,6$ \\
\hline Goodman et al., 2003 & Crianças & $6,9 \pm 1,5$ \\
\hline Armano et al., 2005 & Crianças & $8,8 \pm 2,6$ \\
\hline Reis et al., 2006 & Crianças & $7,8 \pm 1,2$ \\
\hline Lacroix et al., 2007 & Crianças & $\begin{array}{cc}\text { Estratégia } & \text { Estratégia } \\
\text { restritiva } & \text { liberal } \\
6,7 \pm 0,5 & 8,1 \pm 0,1\end{array}$ \\
\hline
\end{tabular}


Hébert et al. demonstraram que uma estratégia restritiva em termos de transfusões de glóbulos vermelhos é adequada, com uma taxa de mortalidade menor do que a observada no grupo controle, que recebeu mais transfusões. Este estudo sugere que concentrações de $\mathrm{Hb}$ acima de $7,0 \mathrm{~g} / \mathrm{dL}$ são suficientes para garantir adequada oferta de oxigênio (Hébert et al., 1999). Da mesma forma, o estudo semelhante realizado em crianças recomendou o emprego da estratégia restritiva em pacientes pediátricos com condições clínicas estáveis internados em centros de terapia intensiva (Lacroix et al., 2007).

A saturação venosa de oxigênio e o lactato sérico arterial são raramente ou nunca utilizados para a indicação de uma transfusão. Em nosso estudo, estas variáveis foram coletadas em 14\% dos casos (24 de 173 eventos transfusionais). Sabe-se que pacientes com Síndrome da Resposta Inflamatória Sistêmica (SIRS) e sepse geralmente apresentam anormalidades no consumo de oxigênio. $O$ tratamento destes pacientes visa otimizar a extração tissular de oxigênio através da manutenção da oferta adequada de oxigênio, reduzindo a progressão da disfunção celular e, por sua vez, evitando a DMOS (Task Force of the American College of Critical Care Medicine, 1999). A $\mathrm{SvO}_{2}$ e o lactato sérico arterial são marcadores valiosos do metabolismo celular como medidas indiretas da oferta de oxigênio aos tecidos. A monitorização da $\mathrm{SvO}_{2}$ avalia o balanço entre a oferta e o consumo de oxigênio, que está diminuído quando há uma oferta diminuída e/ou aumento do consumo. A presença e a persistência de altos níveis de lactato sérico arterial estão relacionadas com aumentos na morbidade e mortalidade (Rivers et al., 2001; Bakker, 1999).

A manutenção de níveis adequados de concentração de hemoglobina foi 
sugerida como um meio de aumentar a oferta de oxigênio aos tecidos na ocorrência de SIRS/sepse. Em estudo recente realizado por Rivers et al., em 2001, a otimização precoce da $\mathrm{SvO}_{2}$ revelou-se eficiente em reduzir a mortalidade em pacientes com sepse severa. Parte da estratégia consistia em manter a taxa de hematócrito acima de 30\%. Devemos lembrar que a transfusão pode também provocar uma diminuição da oferta de oxigênio para os tecidos, devido à redução no fluxo tecidual na microcirculação, por causa do aumento da viscosidade sangüínea. Este efeito pode ser mais severo quando é utilizado sangue estocado (Marik e Sibbald, 1993).

Um estudo realizado em um CTI de São Paulo, com pacientes adultos graves, avaliou os efeitos da transfusão de glóbulos vermelhos na $\mathrm{SvO}_{2}$ e nos níveis de lactato sérico arterial (Mazza et al., 2005). Os autores não observaram diferença estatisticamente significante nos valores de $\mathrm{SvO}_{2}$ e lactato sérico arterial após a realização das transfusões.

Levantamos algumas questões que poderiam justificar a ausência de coleta de lactato sérico arterial pré-transfusão, como a falta do material adequado para pesquisa de lactato sérico arterial no laboratório da instituição, assim como a ausência de solicitação desse exame de rotina por parte da equipe médica. No que concerne à coleta de $\mathrm{SvO}_{2}$, lembramos que nem todos os pacientes têm acesso venoso central durante a internação no CTI, o que impossibilitaria a coleta desse exame.

Com relação ao uso de procedimentos terapêuticos, 82\% (142 de 173 eventos transfusionais) estavam sendo submetidos a algum procedimento terapêutico no momento da indicação da transfusão, sendo a ventilação mecânica o procedimento mais encontrado (70,5\% dos eventos transfusionais). 
Valor muito semelhante foi encontrado no estudo de Reis et al., com freqüência de ventilação mecânica em 83,3\% dos casos (Reis et al., 2006). O estudo realizado por Hébert et al. demonstrou que a transfusão de glóbulos vermelhos não influencia a duração da ventilação mecânica nos pacientes adultos estudados (Hébert et al., 2001).

O estudo em crianças recém-publicado (Lacroix et al., 2007) provavelmente trará grandes mudanças na maneira como o pediatra intensivista conduz pacientes graves, com condições clínicas estáveis, internados em CTI, levando à diminuição da indicação de transfusões de glóbulos vermelhos e menor risco de efeitos adversos e exposição a diversos doadores, sem prejuízo para o tratamento clínico desses pacientes. É nossa intenção realizar estudo semelhante em nosso meio, em futuro próximo.

\section{3 - Considerações finais}

A ocorrência de anemia é comum em pacientes internados em centros de terapia intensiva pediátricos e a forma de tratamento mais utilizada é a transfusão de glóbulos vermelhos. Porém, ainda não existe na literatura um consenso sobre o melhor momento para a indicação dessa transfusão.

Acreditamos que a transfusão de glóbulos vermelhos deve ser realizada em casos específicos, como a presença de choque hipovolêmico por hemorragia aguda ou em pacientes gravemente doentes e instáveis, com anemia concomitante que pode levar à oferta insuficiente de oxigênio aos tecidos. 
Sugerimos que as indicações das transfusões de glóbulos vermelhos sejam criteriosas. Os pacientes devem receber transfusões de glóbulos vermelhos quando apresentam sangramento ativo e hipovolemia severa. Pacientes sem sangramento ativo ou hipovolemia provavelmente terão poucos benefícios com transfusões de glóbulos vermelhos enquanto sua concentração de hemoglobina estiver acima de $7 \mathrm{~g} / \mathrm{dL}$.

Sugerimos, também, que sejam seguidas as recomendações feitas pelo estudo randomizado realizado em crianças, sobre o uso de transfusões de glóbulos vermelhos (Lacroix et al., 2007), reservando o uso das transfusões para os pacientes gravemente doentes com condições clínicas instáveis.

Lembramos, ainda, que a realização de uma transfusão de glóbulos vermelhos depende do altruísmo de doadores de sangue, e que a doação deve ser estimulada e entendida como um meio de ajudar o próximo e salvar vidas. 
6. Conclusões 
1- As transfusões de glóbulos vermelhos são realizadas em todas as idades. Em nosso estudo, a mediana de idade dos pacientes que receberam transfusão foi de 18 meses;

2- A concentração de hemoglobina e a taxa de hematócrito são os principais dados utilizados para a indicação das transfusões de glóbulos vermelhos, sendo que as medianas pré-transfusão foram 7,8 g/dl e $23 \%$, respectivamente;

3- A saturação venosa central de oxigênio e o lactato sérico arterial são pouco utilizados como critérios para a indicação de transfusão de glóbulos vermelhos;

4- A maioria dos pacientes transfundidos é submetida a algum procedimento terapêutico no momento da indicação da transfusão, sendo a ventilação mecânica o procedimento mais prevalente, seguido da utilização de drogas vasoativas. Poucos pacientes que recebem transfusão de glóbulos vermelhos estão em uso de métodos de substituição renal. Em muitos casos são realizadas transfusões de glóbulos vermelhos em pacientes que apresentam disfunção de múltiplos órgãos e sistemas, sendo a disfunção de dois sistemas a mais prevalente. 
7-Anexos 


\section{ANEXO A}

Critérios para falência orgânica segundo Wilkinson et al., 1986

\begin{tabular}{|c|c|}
\hline Sistema orgânico & Critérios \\
\hline Cardiovascular & $\begin{array}{l}\mathrm{PAM}<40 \mathrm{mmHg} \text { (crianças }<12 \text { meses) } \\
\mathrm{PAM}<50 \mathrm{mmHg} \text { (crianças }>12 \text { meses) } \\
\mathrm{FC}<50 \mathrm{bpm} \mathrm{ou}>220 \mathrm{bpm} \text { (crianças }<12 \text { meses) } \\
\mathrm{FC}<40 \mathrm{bpm} \text { ou }>200 \mathrm{bpm} \text { (crianças }>12 \text { meses) } \\
\text { Parada cardíaca } \\
\mathrm{pH} \text { sérico }<7,20 \text { (com } \mathrm{PaCO}_{2} \text { normal) } \\
\text { Infusão contínua de droga vasoativa para suporte } \\
\text { hemodinâmico }\end{array}$ \\
\hline Respiratório & $\begin{array}{l}\mathrm{FR}>90 / \text { min (crianças }<12 \text { meses) } \\
\mathrm{FR}>70 / \text { min (crianças }>12 \text { meses) } \\
\mathrm{PaO}_{2}<40 \text { torr (ausência de cardiopatia cianótica) } \\
\mathrm{PaO}_{2} / \mathrm{FiO} 2<200 \text { (ausência de cardiopatia cianótica) } \\
\mathrm{PaCO}_{2}>65 \text { torr } \\
\text { Ventilação mecânica (>24 h se pós-operatório) }\end{array}$ \\
\hline Neurológico & $\begin{array}{l}\text { Glasgow < } 5 \\
\text { Midríase fixa bilateral }\end{array}$ \\
\hline Hematológico & $\begin{array}{l}\text { Hemoglobina }<5 \mathrm{~g} / \mathrm{dl} \\
\text { Glóbulos brancos }<3000 \text { células } / \mathrm{mm}^{3} \\
\text { Plaquetas }<20.000 / \mathrm{mm}^{3}\end{array}$ \\
\hline Renal & $\begin{array}{l}\text { Uréia sérica }>100 \mathrm{mg} / \mathrm{dl} \\
\text { Creatinina sérica } \geq 2 \mathrm{mg} / \mathrm{dl} \text { (na ausência de doença } \\
\text { renal pré-existente) } \\
\text { Diálise }\end{array}$ \\
\hline
\end{tabular}

DMOS: presença de um ou mais critérios para cada sistema e incidência de, no mínimo, dois sistemas orgânicos alterados.

PAM: Pressão arterial média

FC: Freqüência cardíaca

FR: Freqüência respiratória

$\mathrm{PaCO}_{2}$ : Pressão parcial de dióxido de carbono

$\mathrm{PaO}_{2}$ : Pressão parcial de oxigênio

$\mathrm{PaO}_{2} / \mathrm{FiO}_{2}$ : Relação entre pressão parcial de oxigênio e fração inspirada de oxigênio 


\section{ANEXO B}

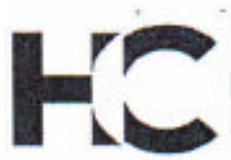

MoSPITAL DAS gLinIEAS

SA PACULDADE OX GOLDICINA

\section{APROVAÇÃO}

A Comissão de Ética para Análise de Projetos de Pesquisa - CAPPesq da Diretoria Clínica do Hospital das Clínicas e da Faculdade de Medicina da Universidade de São Paulo, em sessão de 28.09.06, APROVOU as mudanças referente ao Protocolo de Pesquisa $n^{\circ}$ 737/03, intitulado: "Estudo prospectivo da prática em transfusão de glóbulos vermelhos $e$ índice de oxigenação em um Centro de Terapia Intensiva Pediátrico"apresentado pelo Departamento de PEDIATRIA.

- Alteração de Pesquisador Responsável para: DR. EDUARDO JUAN TROSTER e Pesquisadora Executante: Ora. Cibele Mendes

- Alteração de Título para: "Prática em transfusão de glóbulos vermelhos e índice de oxigenaçäo em um centro de terapia intensiva pediátrica":

- Exclusão do Hospital Israelita Albert Einstein na Pesquisa:

- Alteração no Protocolo de Pesquisa conforme carta datada de 04/09/06.

CAPPesq, 28 de Setembro de 2006.

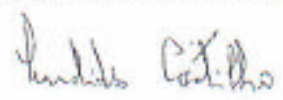

PROF. DR. EUCLIDES AYRES DE CASTILHO Presidente da Comissão de Ética para Análise de Projetos de Pesquisa

Comirsolo de Étice para Análise de frojetes de Peecussa de HCFMUSP e da FMUSP Direterie Olriea do Hossital das Clinicas da Faculdode de Medicina da Universidede de Sto Paulo Ausa Cvidia Pines de Campos, $225,5^{\circ}$ endar - CEP 05403010 - S30 Paub - SP

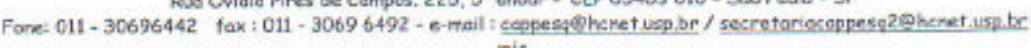


8-Referências 
American Society of Anesthesiologists. Practice guidelines for blood component therapy. Anesthesiology. 1996;84:732-47.

American Society of Anesthesiologists. Practice guidelines for perioperative blood transfusion and adjuvant therapies - An updated report by the American Society of Anesthesiologists Task Force on Perioperative Blood Transfusion and Adjuvant Therapies. Anesthesiology. 2006;105:198-208.

Armano R, Gauvin F, Ducruet T, Lacroix J. Determinants of red blood cell transfusions in a pediatric critical care unit: a prospective, descriptive epidemiological study. Crit Care Med. 2005;33:2637-44.

Bakker J. Blood lactate levels. Curr Opin Crit Care. 1999;5:234-9.

Beal AL, Cerra FB. Multiple organ failure syndrome in the 1990s. Systemic inflammatory response and organ dysfunction. JAMA. 1994;226:33.

Blumberg N, Heal JM. Immunomodulation by blood transfusion: an evolving scientific and clinical challenge. Am J Med. 1996;101:299-308.

Cassut M, Seifert B, Pasch T, Schmid ER, Turina MI, Spahn DR. Factors influencing the individual effects of blood transfusions on oxygen delivery and oxygen consumption. Crit Care Med. 1999;27:2194-200. 
Cohen A, Manno C. Transfusion practices in infants receiving assisted ventilation. Clin Perinatol. 1998;25:97-111.

Corwin HL, Gettinger A, Pearl RG, Fink MP, Levy MM, Abraham E, MacIntyre NR, Shabot MM, Duh M-S, Shapiro MJ. The CRIT Study: Anemia and blood transfusion in the critically ill - Current clinical practice in the United States. Crit Care Med. 2004;32:39-52.

Dennis RC, Clas D, Niehoff JM, Yeston NS. Transfusion therapy. In: Civetta JM, Taylor RW, Kirby RR. Critical Care. $3^{\mathrm{a}}$ ed. Philadelphia: Lippincott Raven; 1997. p.639-59.

Desmet L, Lacroix J. Transfusion in pediatrics. In: Corwin HL, Hébert PC. Critical Care Clinics - Blood Transfusion in the Critically III. Philadelphia: Saunders; 2004. v.20, p.299-311.

Dudell G, Cornish JD, Bartlett RH. What constitutes adequate oxygenation? Pediatrics. 1990;85:39-41.

Dorlhiac-Lhacer PE. Doação de sangue e testes laboratoriais no sangue do doador. In: Chamone DAF, Novaretti MCZ, Dorlhiac-Lhacer PE. Manual de transfusão sangüínea. São Paulo: Roca; 2001. p.1-8. 
Ferreira JS, Ferreira VLPC, Pelandré GL. Transfusão de concentrado de hemácias em Unidade de Terapia Intensiva - Red blood cell transfusion in the Intensive Care Unit. Rev Bras Hematol Hemoter. 2005;27:179-82.

Galel SA, Malone III JM, Viele MK. Transfusion Medicine. In: Greer JP, Foerster J, Lukens JN, Rodgers GM, Paraskevas F, Glader B. Wintrobe's Clinical Hematology $11^{\underline{a}}$ ed. Philadelphia: Lippincott Williams \& Wilkins; 2004. v.1. p.831-82.

Goodman AM, Pollack MM, Patel KM, Luban NLC. Pediatric red blood cell transfusions increase resource use. J Pediatr. 2003;142:123-7.

Goodnough LT, Brecher ME, Kanter MH, AuBuchon JP. Blood transfusion.

N Engl J Med. 1999;340:438-47.

Groeger JS, Guntupalli KK, Strosberg M, Halpern N, Raphaely RC, Cerra F, Kaye W. Descriptive analysis of critical care units in the United States: patient characteristics and intensive care unit utilization. Crit Care Med. 1993;21:279-91.

Halsman M. Anemias: considerações gerais e diagnóstico diferencial. In: Marcondes E, FAC Vaz, Ramos JLA, Okay Y. Pediatria básica. 9ae ed. São Paulo: Sarvier; 2003. Tomo 2. p.657-9. 
Hébert PC, Blajchman MA, Cook DJ, Yetisir E, Wells G, Marshall J, Schweitzer I, the Transfusion Requirements In Critical Care Investigators For The Canadian Critical Care Trials Group. Do blood transfusions improve outcomes related to mechanical ventilation? Chest. 2001;119:1850-7.

Hébert PC, Linden PV, Biro G, Hu LQ. Physiologic aspects of anemia. In: Corwin HL, Hébert PC. Critical Care Clinics - Blood Transfusion in the Critically III. Philadelphia: Saunders; 2004a. v.20, p.187-212.

Hébert PC, McDonald BJ, Tinmouth A. Clinical consequences of anemia and red cell transfusion in the critically ill. In: Corwin HL, Hébert PC. Critical Care Clinics - Blood Transfusion in the Critically III. Philadelphia: Saunders; 2004b. v.20, p.225-35.

Hébert PC, Wells G, Blajchman MA, Marshall J, Martin C, Pagliarello G, Tweeddale M, Schweitzer I, Yetisir E, the Transfusion Requirements In Critical Care Investigators For The Canadian Critical Care Trials Group. A multicenter, randomized, controlled clinical trial of transfusion requirements in critical care. N Engl J Med. 1999;340:409-17.

Hébert PC, Wells G, Martin C, Tweeddale M, Marshall J, Blajchman M, Pagliarello G, Schweitzer I, Calder L. A Canadian survey of transfusion practices in critically ill patients. Crit Care Med. 1998;26:482-7. 
Hébert PC, Wells G, Tweeddale M, Martin C, Marshall J, Pham B, Blajchman M, Schweitzer I, Pagliarello G. Does transfusion practice affect mortality in critically ill patients? Am J Respir Crit Care Med. 1997;155:161823.

Hutton B, Fergusson D, Tinmouth A, Mclntyre L, Kmetic A, Hébert PC. Transfusion rates vary significantly amongst Canadian medical centres. Can J Anesth. 2005;52:581-90.

Junqueira PC, Rosenblit J, Hamerschlak N. História da Hemoterapia no Brasil. Rev Bras Hematol Hemoter. 2005;27:201-7.

Kalil Filho WJ, Delgado AF, Schvartsman BGS, Kimura HM. Análise clínica e prognostica da Síndrome de Disfunção Orgânica Múltipla. Pediatria (São Paulo). 1995;17:143-7.

Kevy SV, Gorlin JB. Red Cell Transfusion. In: Nathan DG, Orkin SH. Nathan and Oski's - Hematology of Infancy and Childhood. $5^{\text {th }}$ ed. Philadelphia: W.B.Saunders Company; 1998. v.2, p.1784-801.

Lacroix J, Hébert PC, Hutchison JS, Hume HA, Tucci M, Ducruet T, Gauvin F, Collet J-P, Toledano BJ, Robillard P, Joffe A, Biarent D, Meert K, Peters MJ, for the TRIPICU Investigators, the Canadian Critical Care Trials Group, and the Pediatric Acute Lung Injury and Sepsis Investigators Network. 
Transfusion strategies for patients in pediatric intensive care units. $N$ Engl $J$ Med. 2007;356:1609-19.

Lanzkowsky P. Manual of Pediatric Hematology and Oncology. $3^{\underline{a}}$ ed. San Diego: Academic Press; 2000. p.751-4.

Laverdière C, Gauvin F, Hébert PC, Infante-Rivard C, Hume H, Toledano BJ, Guertin MC, Lacroix J, the Canadian Critical Care Trials Group. Survey on transfusion practices of pediatric intensivists. Pediatr Crit Care Med. 2002;3:335-40.

Leteurtre S, Martinot A, Duhamel A, Proulx F, Grandbastien B, Cotting J, Gottesman R, Joffe A, Pfenninger J, Hubert P, Lacroix J, Leclerc F. Validation of the paediatric logistic organ dysfunction (PELOD) score: prospective, observational, multicentre study. Lancet. 2003;362:192-7.

Marik PE, Sibbald WJ. Effect of stored-blood transfusion on oxygen delivery on patients with sepsis. JAMA. 1993;269:3024-9.

Mazza BF, Machado FR, Mazza DD, Hassman V. Evaluation of blood transfusion effects on mixed venous oxygen saturation and lactate levels in patients with SIRS/Sepsis. Clinics. 2005;60:311-6.

Napolitano LM. Scope of the problem: epidemiology of anemia and use of blood transfusions in critical care. Critical Care. 2004;8(Suppl 2):S1-8. 
Neto SW. Hemoterapia. In: Verrastro T, Lorenzi TF, Neto SW. Hematologia e hemoterapia - Fundamentos de morfologia, fisiologia, patologia e clínica. São Paulo: Atheneu; 2005. p.237-53.

Oliveira MRAA. Hematologia Básica. 2ª ed. São Paulo: American Med Editora Ltda; 1998. Cap.6, p.65-7: Anemias.

Oski FA, Brugnara C, Nathan DG. A diagnostic approach to the anemic patient. In: Nathan DG, Orkin SH. Nathan and Oski's - Hematology of infancy and childhood. 5르. ed. Philadelphia: W.B. Saunders Company; 1998. v.1. p.375-84.

Oski FA, Brugnara C, Nathan DG. A diagnostic approach to the anemic patient. In: Nathan DG, Orkin SH, Ginsburg D, Look AT. Hematology of infancy and childhood. 6ª ed. Philadelfia: Saunders; 2003. v.1. p.409-18.

Popovsky MA, Moore SB. Diagnostic and pathogenetic considerations in transfusion-related injury. Transfusion. 1985;25:573-7.

Proulx F, Fayon M, Farrell CA, Lacroix J, Gauthier M. Epidemiology of sepsis and multiple organ dysfunction syndrome in children. Chest. 1996;109:1033-7. 
Proulx F, Gauthier M, Nadeau D, Lacroix J, Farrel CA. Timing and predictors of death in pediatric patients with multiple organ system failure. Crit Care Med. 1994;22:1025-31.

Rao MP, Boralessa H, Morgan C, Soni N, Goldhill DR, Brett SJ, Boralessa $\mathrm{H}$, Contreras M. Blood component use in critically ill patients. Anaesthesia. 2002;57:530-4.

Reis MA, Felix RJS, Góes PF, Hsin SH, Ventura AMC, Barreira ER, Souza DC. Prática transfusional em unidade de terapia intensiva pediátrica de hospital universitário. Rev Bras Ter Intensiva. 2006;(Suppl I):207-8.

Rivers E, Nguyen B, Havstad S, Ressler J, Muzzin A, Knoblich B, Peterson E, Tomlanovich M, for the Early Goal-Directed Therapy Collaborative Group. Early goal-directed therapy in the treatment of severe sepsis and septic shock. N Engl J Med. 2001;345:1368-77.

Rivers E, Ander DS, Powell D. Central venous oxygen saturation monitoring in the critically ill patient. Curr Opin Crit Care. 2001;7:204-11.

Schroeder ML. Principles and practice of transfusion medicine. In: Lee GR, Foerster J, Lukens J, Paraskevas F, Greer JP, Rodgers GM. Wintrobe's Clinical Hematology. 10ª ed. Baltimore: Williams \& Wilkins; 1999. v.1. p.81773. 
Shander A. Anemia in the critically ill. In: Corwin HL, Hébert PC. Critical Care Clinics - Blood Transfusion in the Critically III. Philadelphia: Saunders; 2004. v.20, p.159-78.

Shorr AF, Jackson WL. Transfusion practice in the ICU: when will we apply the evidence? Chest. 2005;127:702-5.

Surgenor SD, Hampers MJ, Corwin HL. Is blood transfusion good for the heart? Crit Care Med. 2001;29(Suppl 9):189-91.

Task Force of the American College of Critical Care Medicine: Practice parameters for hemodynamic support of sepsis in adult patients in sepsis. Crit Care Med. 1999;27:639-60.

Titlestad K, Georgsen J, Jorgensen J, Kristensen T. Monitoring transfusion practices at two university hospitals. Vox Sang. 2001;80:40-7.

Vincent JL, Baron J-F, Reinhart K, Gattinoni L, Thijs L, Webb A, MeierHellmann A, Nollet G, Peres-Bota D, ABC Investigators. Anemia and blood transfusion in critically ill patients. JAMA. 2002;288:1499-507.

Von Ahsen N, Müller C, Serke S, Frei U, Eckardt KU. Important role of nondiagnostic blood loss and blunted erythropoietic response in the anemia of medical intensive care patients. Crit Care Med. 2001;29:141-50. 
Wardle SP, Weindling AM. Peripheral fractional oxygen extraction and other measures of tissue oxygenation to guide blood transfusions in preterm infants. Semin Perinatol. 2001;25:60-4.

Waxman K. Oxygen delivery and resuscitation. Ann Emerg Med. $1986 ; 15: 1420-2$.

Weiskopf RB, Viele MK, Feiner J, Kelley S, Lieberman J, Noorani M, Leung JM, Fisher DM, Murray WR, Toy P, Moore MA. Human cardiovascular and metabolic response to acute, severe isovolemic anemia. JAMA. 1998;279:217-21.

Wilkinson JD, Pollack MM, Ruttimann UE, Glass NL, Yeh TS. Outcome of pediatric patients with multiple organ system failure. Crit Care Med. $1986 ; 14: 271-4$.

Wilkinson JD, Pollack MM, Glass NL, Kanter RK, Katz RW, Steinhart CM. Mortality associated with multiple organ system failure and sepsis in pediatric intensive care unit. J Pediatr. 1987;111:324-8. 